\title{
Turbopump Design and Analysis Approach for Nuclear Thermal Rockets
}

\author{
Shu-cheng S. Chen ${ }^{1}$, Joseph P. Veres ${ }^{2}$, and James E. Fittje ${ }^{3}$ \\ ${ }^{I}$ NASA Glenn Research Center, Cleveland, Ohio 44135 \\ ${ }^{2}$ Chief, Compressor Branch, NASA Glenn Research Center, Cleveland, Ohio 44135 \\ ${ }^{3}$ Analex Corporation, 1100 Apollo Drive, Brook Park, Ohio 44142 \\ ${ }^{1}$ (216) 433-3585,shu-cheng.s.chen@nasa.gov
}

\begin{abstract}
A rocket propulsion system, whether it is a chemical rocket or a nuclear thermal rocket, is fairly complex in detail but rather simple in principle. Among all the interacting parts, three components stand out: they are pumps and turbines (turbopumps), and the thrust chamber. To obtain an understanding of the overall rocket propulsion system characteristics, one starts from analyzing the interactions among these three components. It is therefore of utmost importance to be able to satisfactorily characterize the turbopump, level by level, at all phases of a vehicle design cycle. Here at NASA Glenn Research Center, as the starting phase of a rocket engine design, specifically a Nuclear Thermal Rocket Engine design, we adopted the approach of using a high level system cycle analysis code (NESS) to obtain an initial analysis of the operational characteristics of a turbopump required in the propulsion system. A set of turbopump design codes (PumpDes and TurbDes) were then executed to obtain sizing and performance characteristics of the turbopump that were consistent with the mission requirements. A set of turbopump analyses codes (PUMPA and TURBA) were applied to obtain the full performance map for each of the turbopump components; a two dimensional layout of the turbopump based on these mean line analyses was also generated. Adequacy of the turbopump conceptual design will later be determined by further analyses and evaluation. In this paper, descriptions and discussions of the aforementioned approach are provided and future outlooks are discussed.
\end{abstract}

Keywords: Turbopump; Nuclear Thermal Rocket Engine; Conceptual Design; System Analysis. 

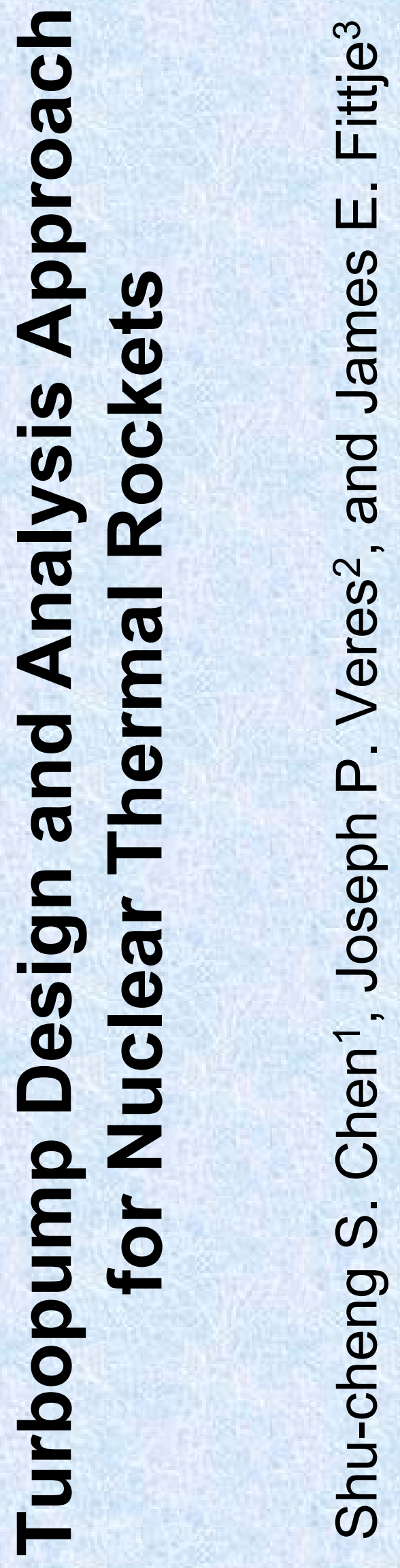

$\omega$

$\frac{\mathscr{\varepsilon}}{\bar{\sigma}}$

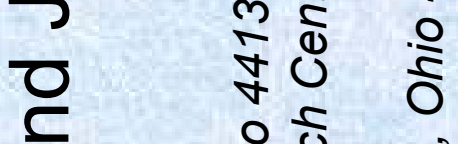

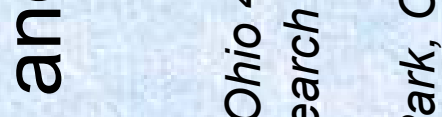

1.

(1) क्ष

(1) ब हूँ

(1) ग $\frac{7}{0}$

$>\quad \frac{1}{2}$

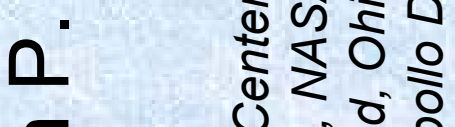

ह

(1) ते बे

( ) कूष

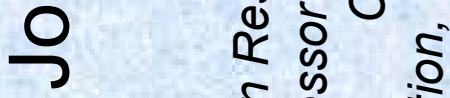

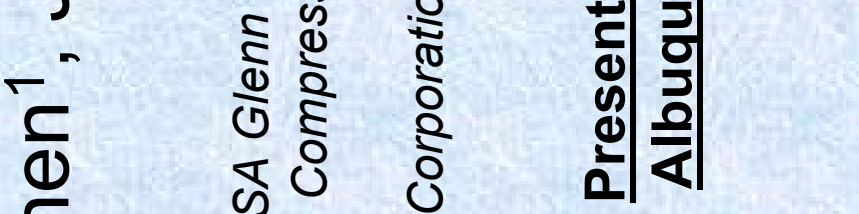

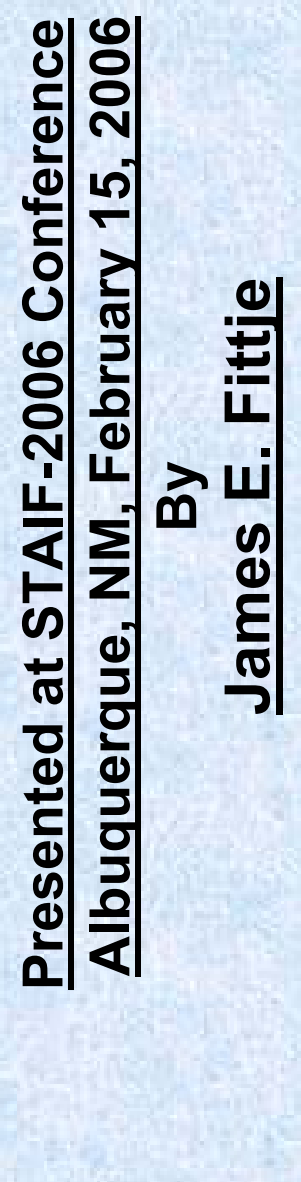

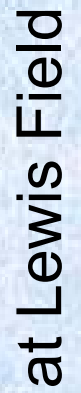

U

ci

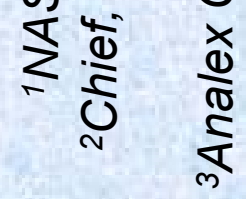



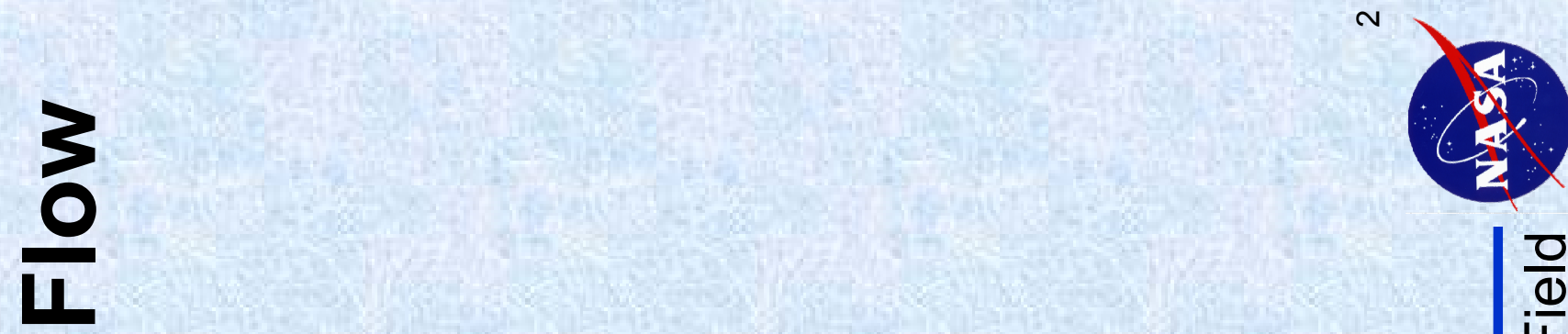

10

10

0

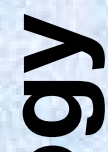

0
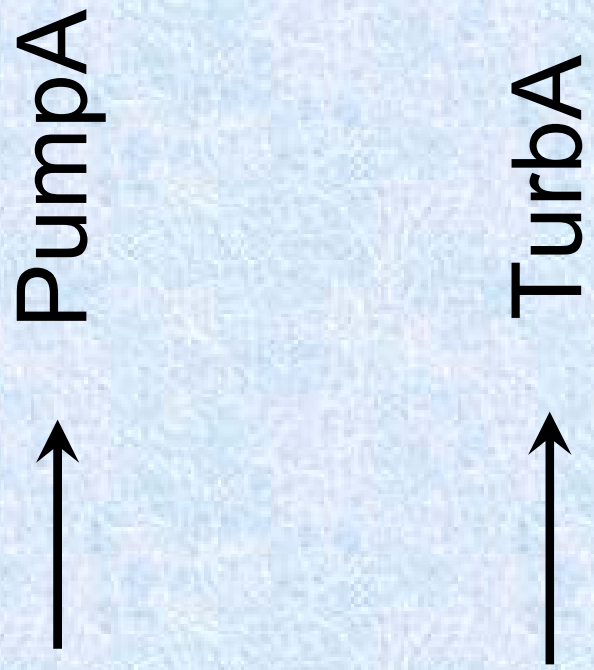

음

0

20

0

(a)

(1)

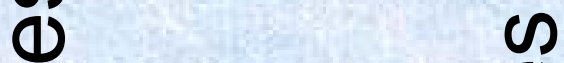

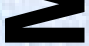

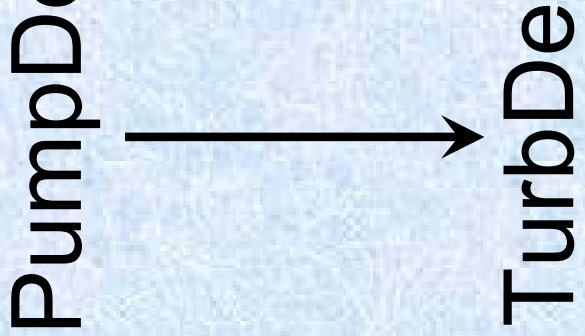

()

0
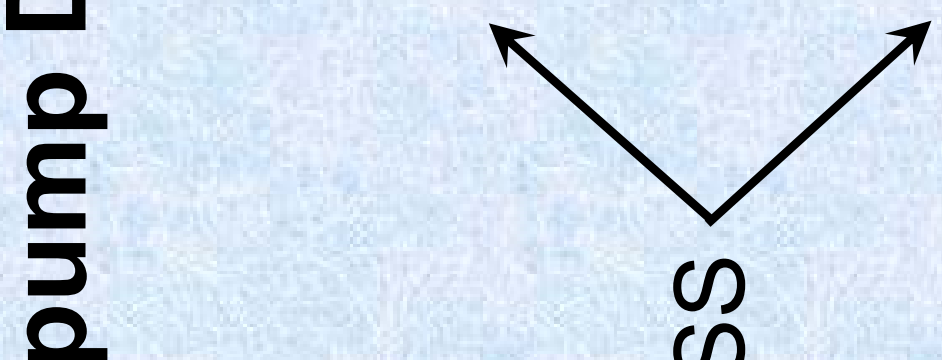

(1)

$\omega$

(

Z

0

0 


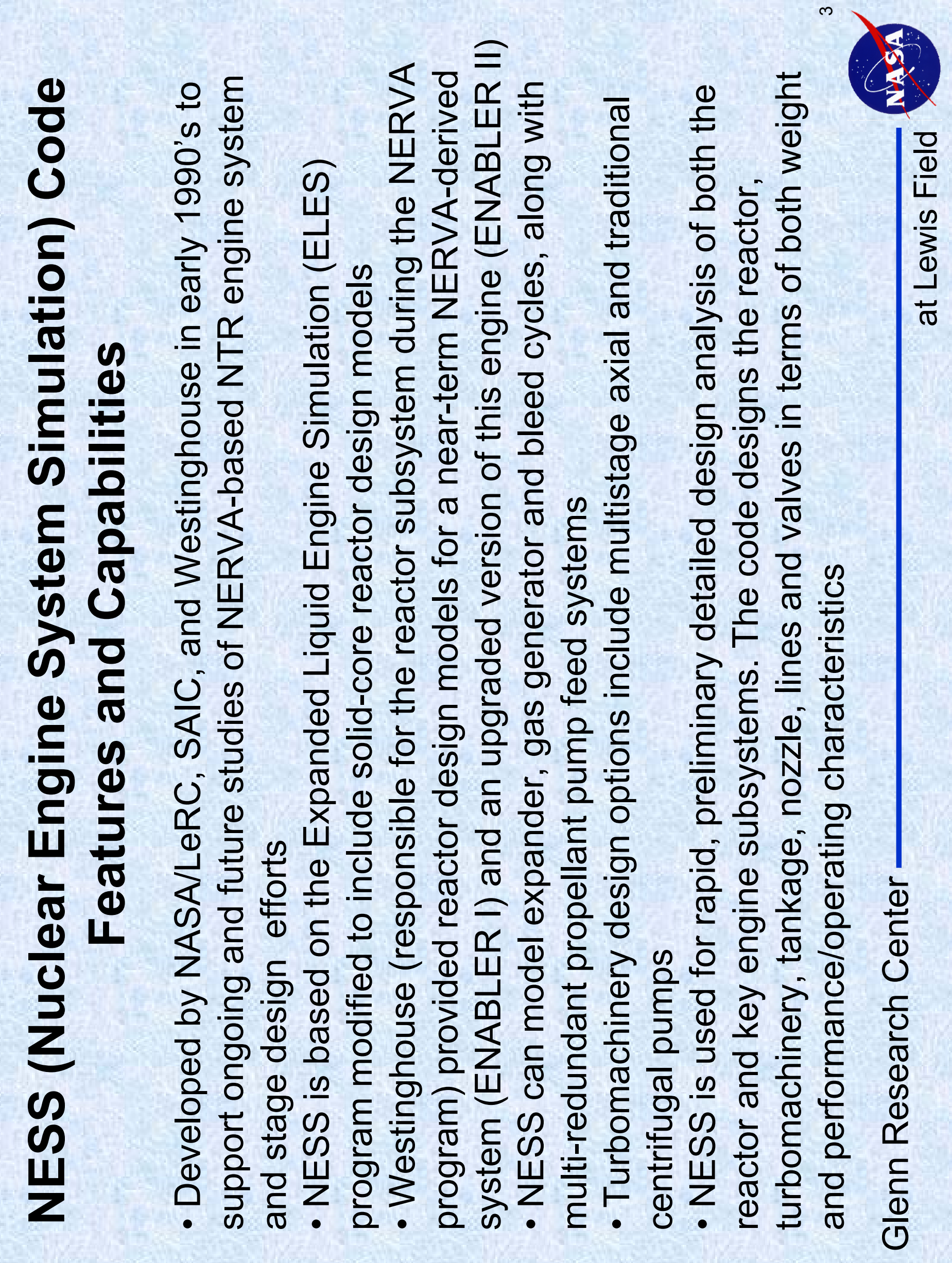


$\frac{1}{2}$

()

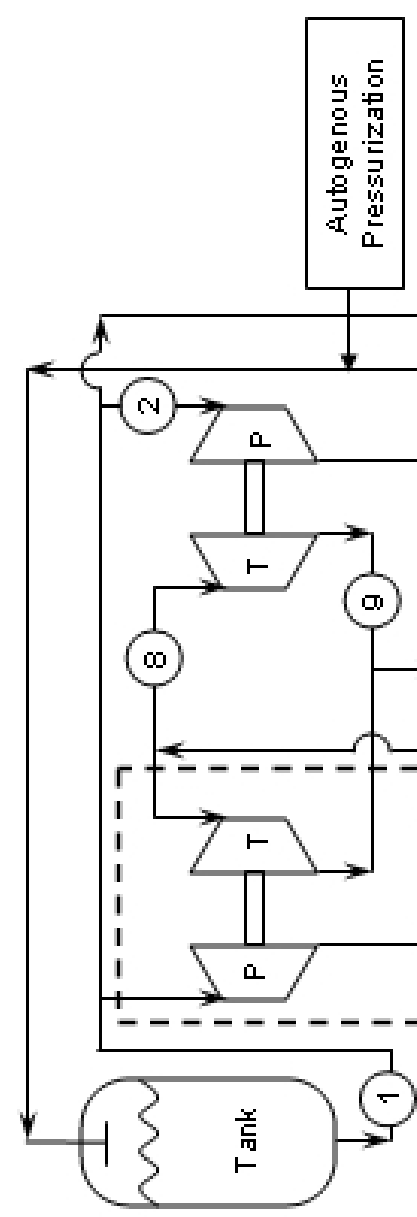

崖.

(1)

$\rightarrow 5$

(1) $\frac{1}{2}$

(a) 巳

(0)

10

C

$\infty$

II

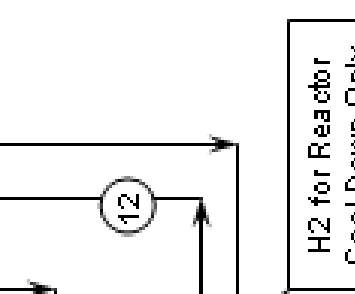




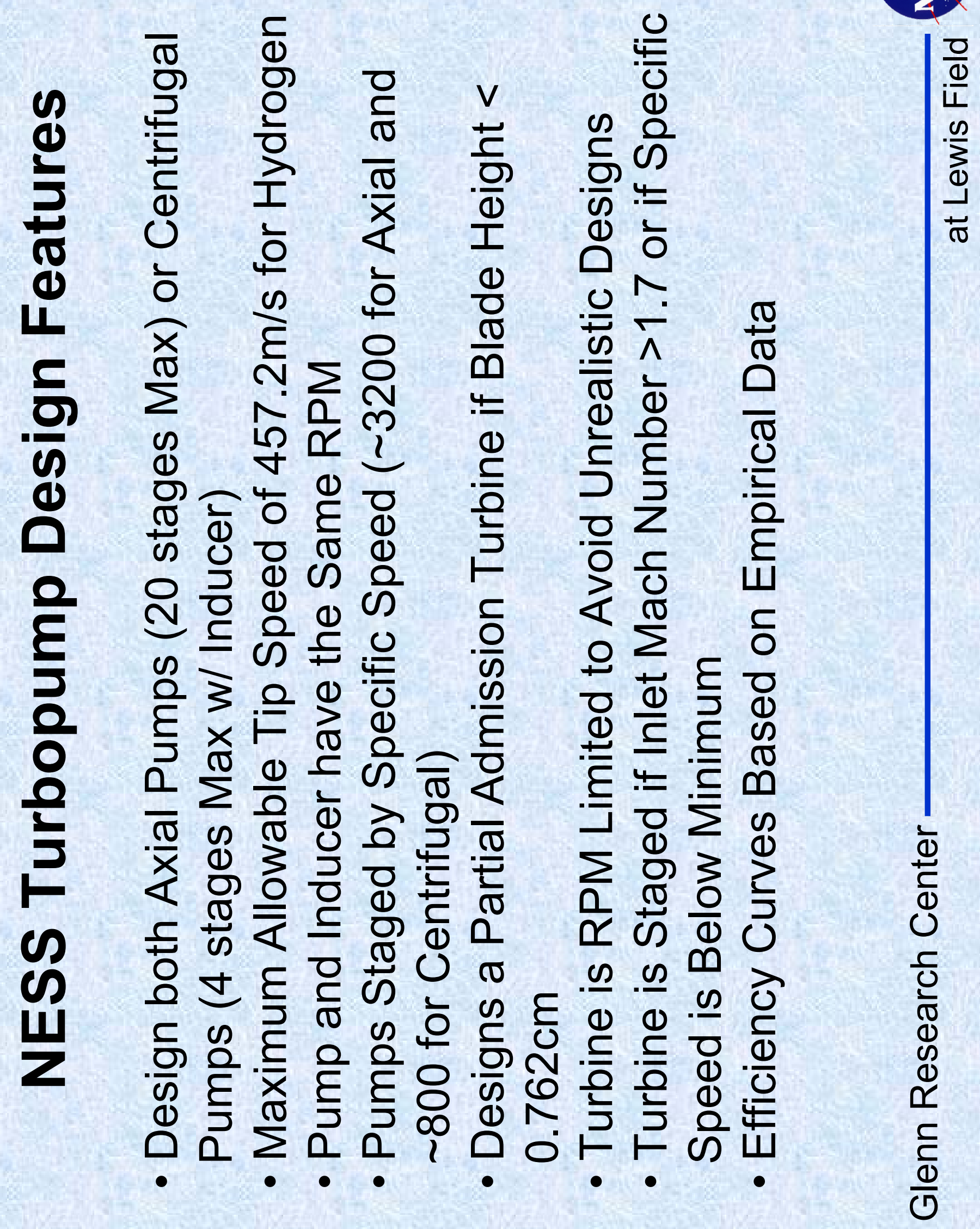




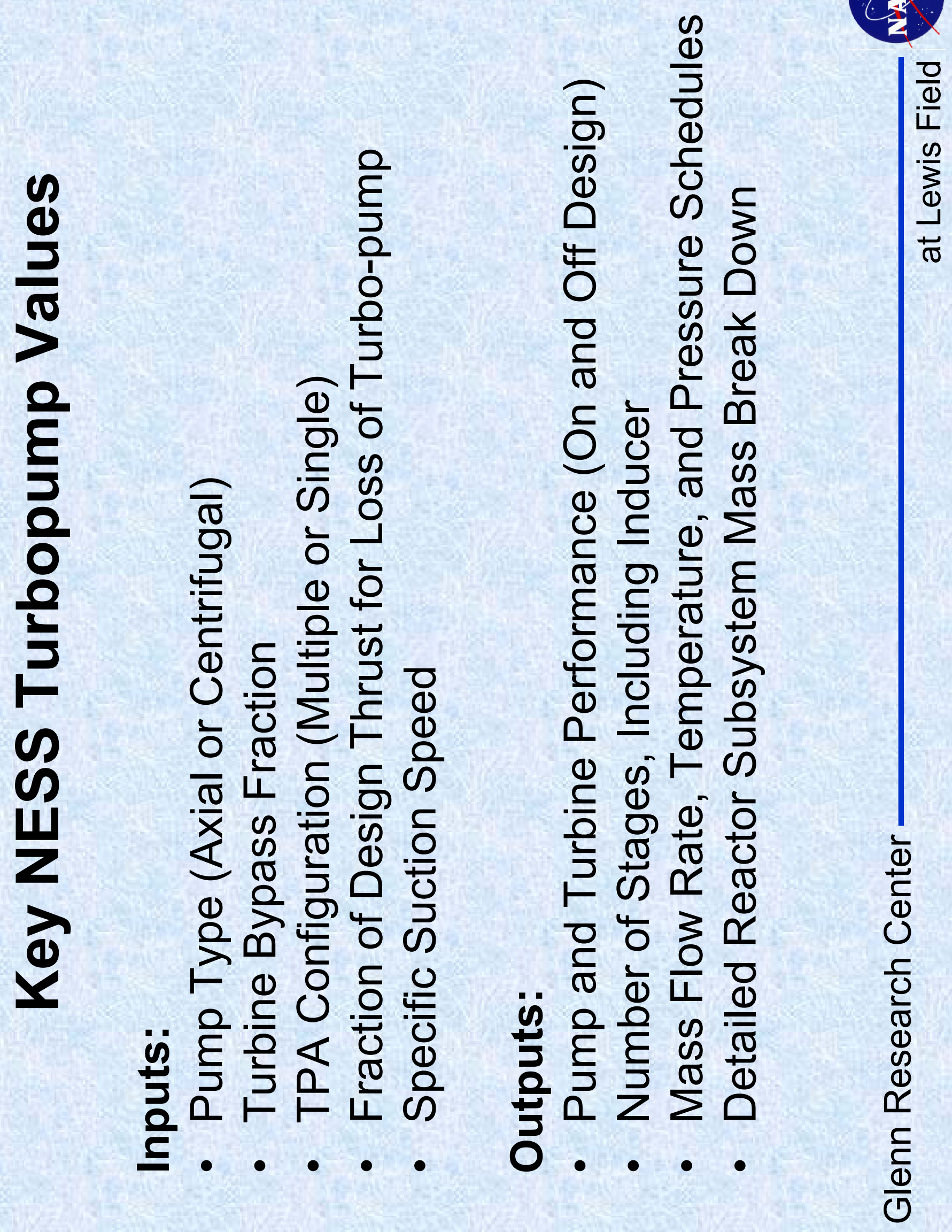




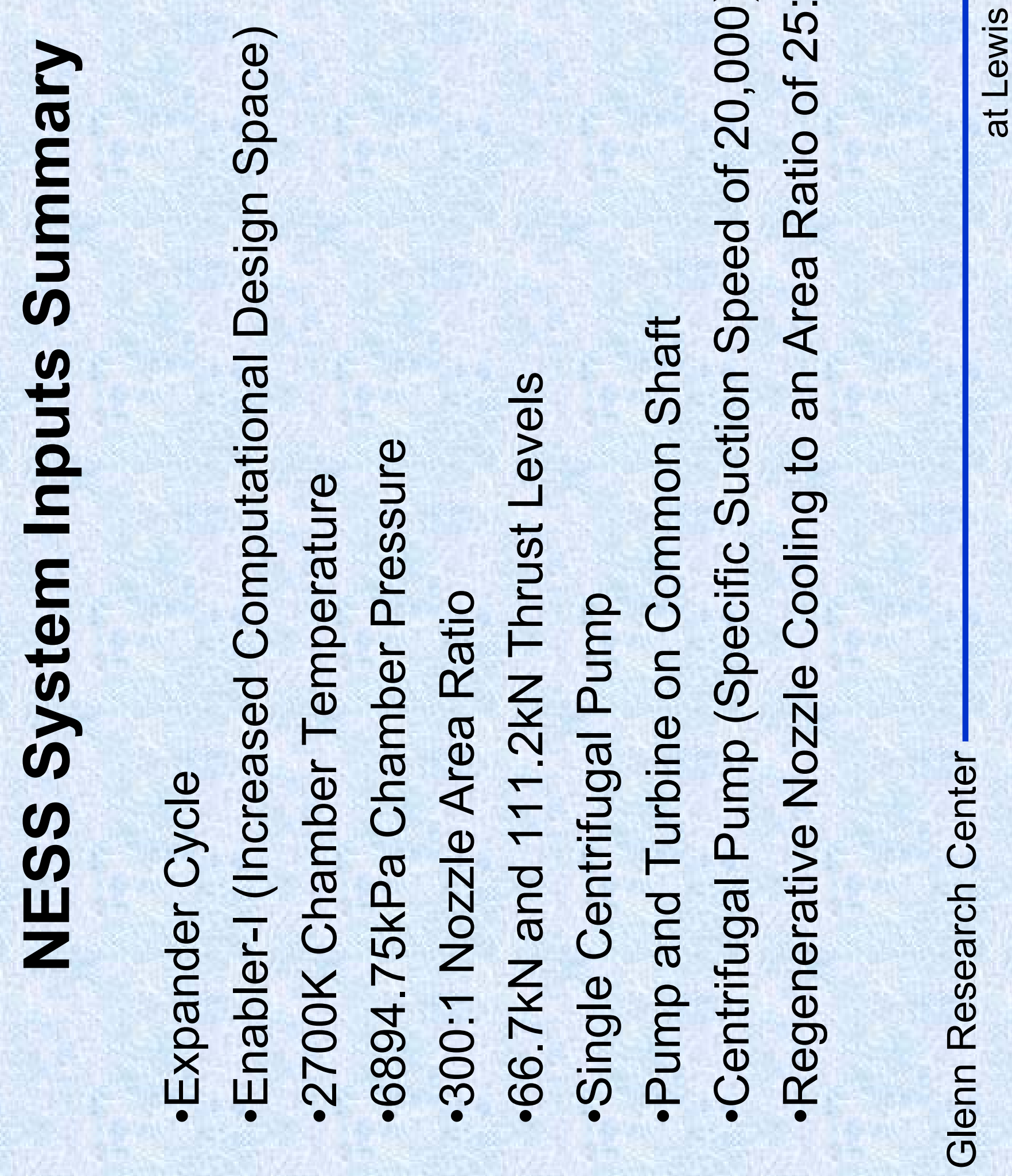




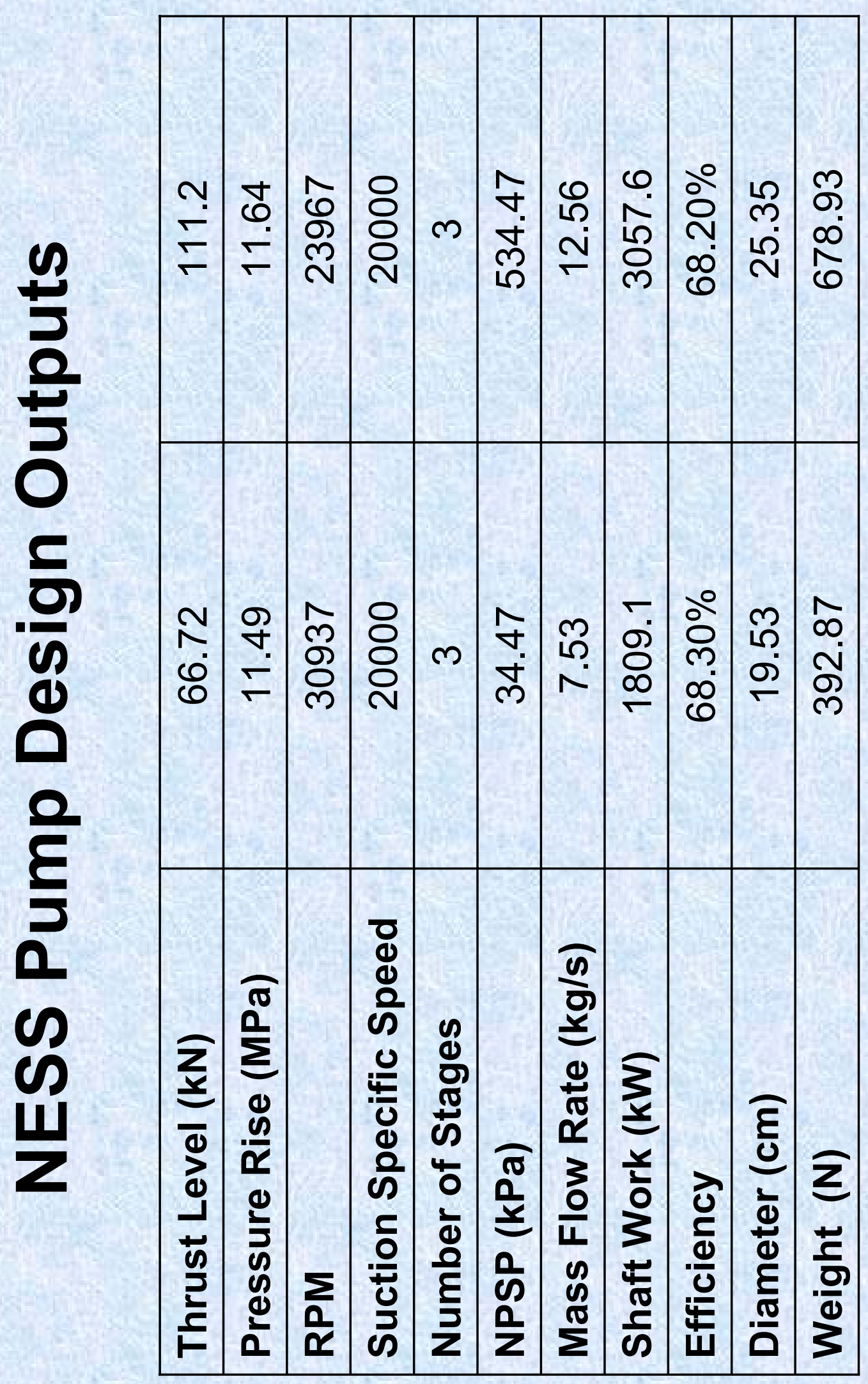

$\frac{0}{\frac{0}{0}}$

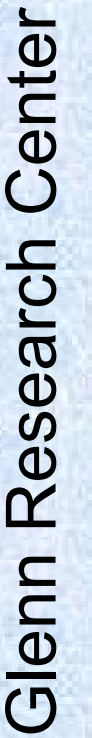




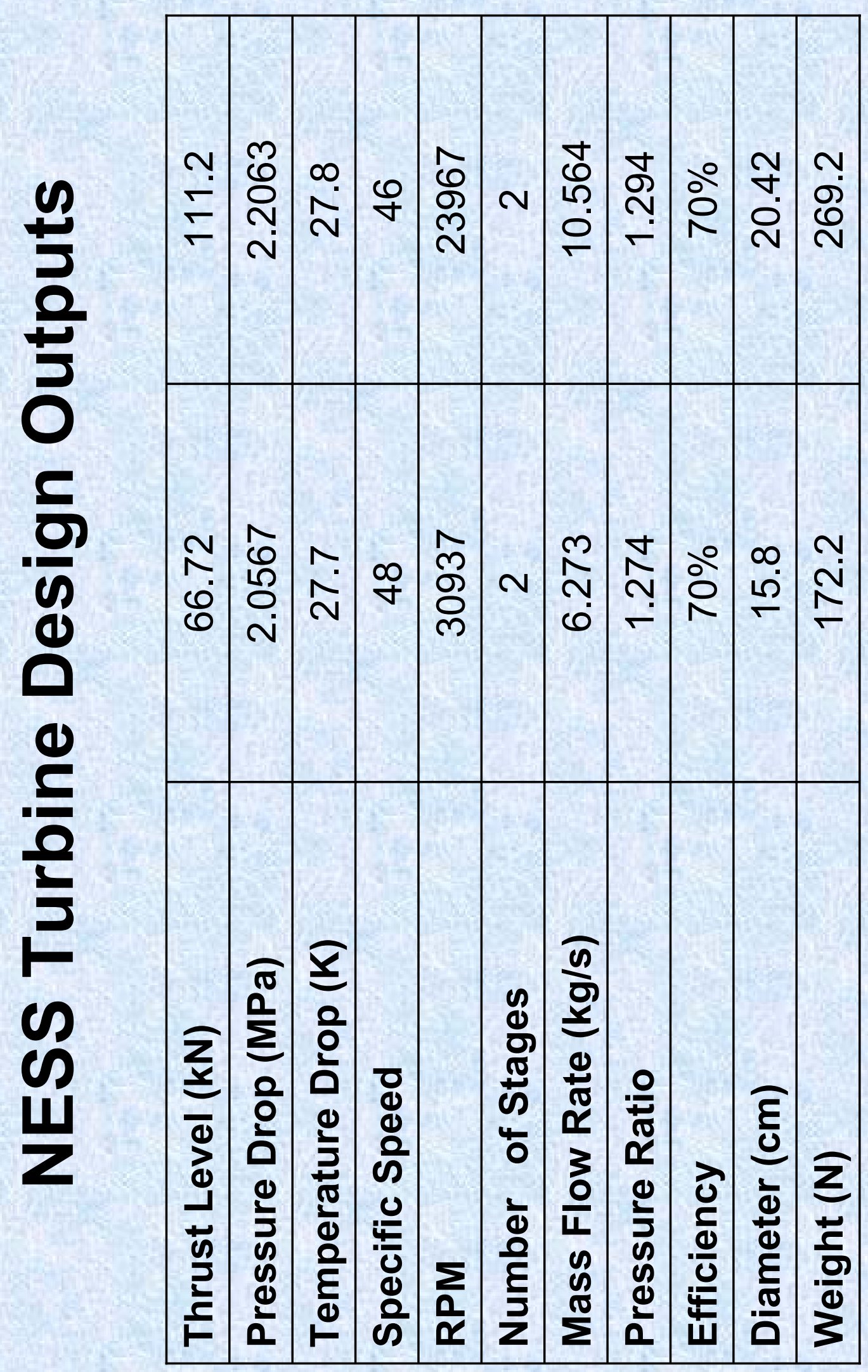

$\frac{0}{\frac{0}{0}}$

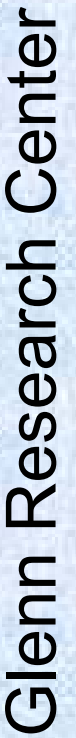


0
0
0

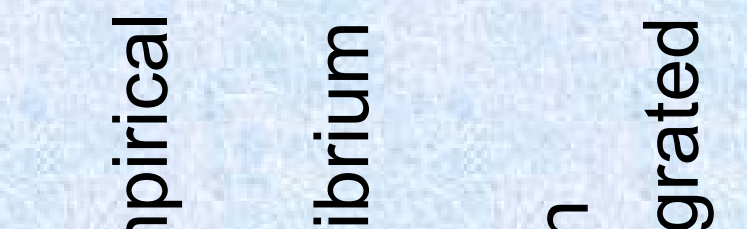

둥

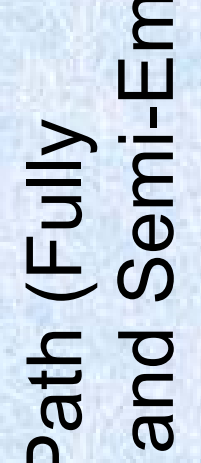

은 $\stackrel{ }{\frac{D}{ \pm}}$

O

$\frac{\frac{0}{0}}{\frac{0}{41}}$

(ด

- $\quad \frac{0}{\circ}$ ठ

는

○

응

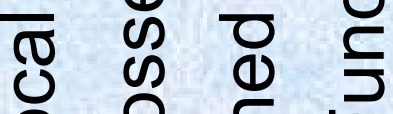

0 O ㄴ

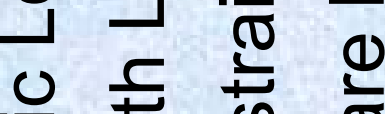

त थ त

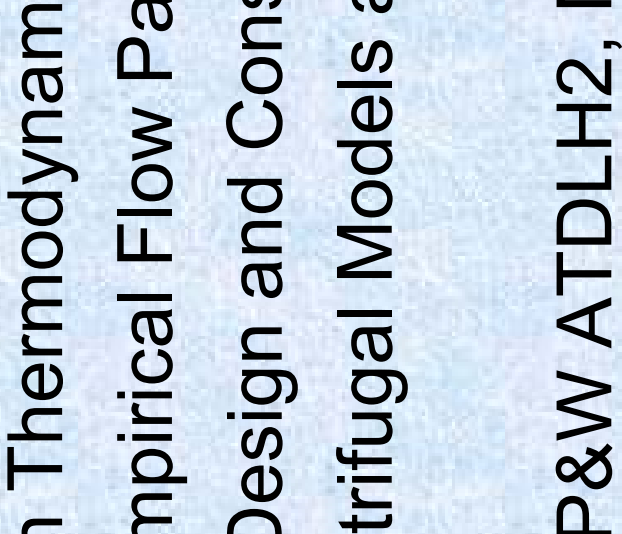

口

g

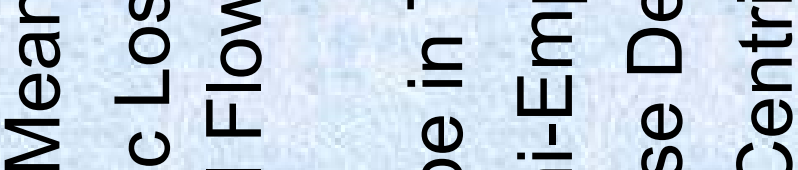

ษ

$\stackrel{1}{\Sigma}$

$\frac{\sqrt{2}}{\frac{1}{1}}$

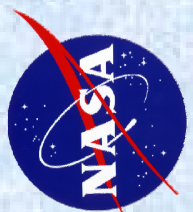

$0_{1}^{-1}$

เก

$\underset{\Sigma}{\Sigma}$

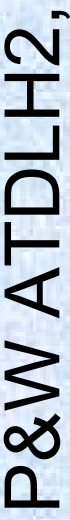

ปे

○ ब

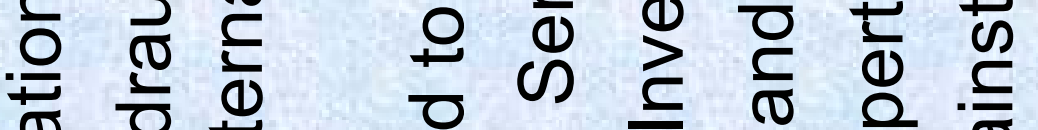

क त

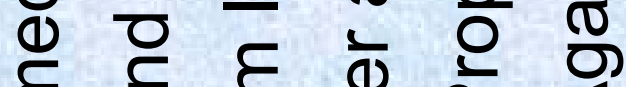

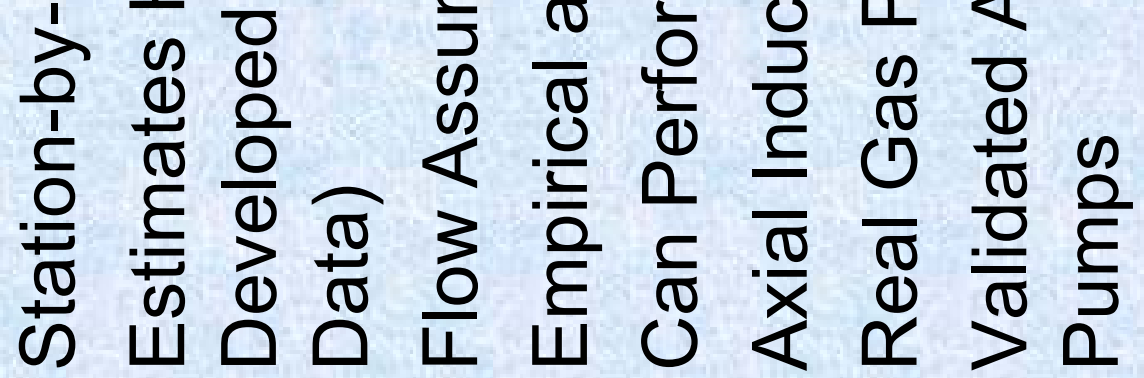

ह ते है ญ

ด 

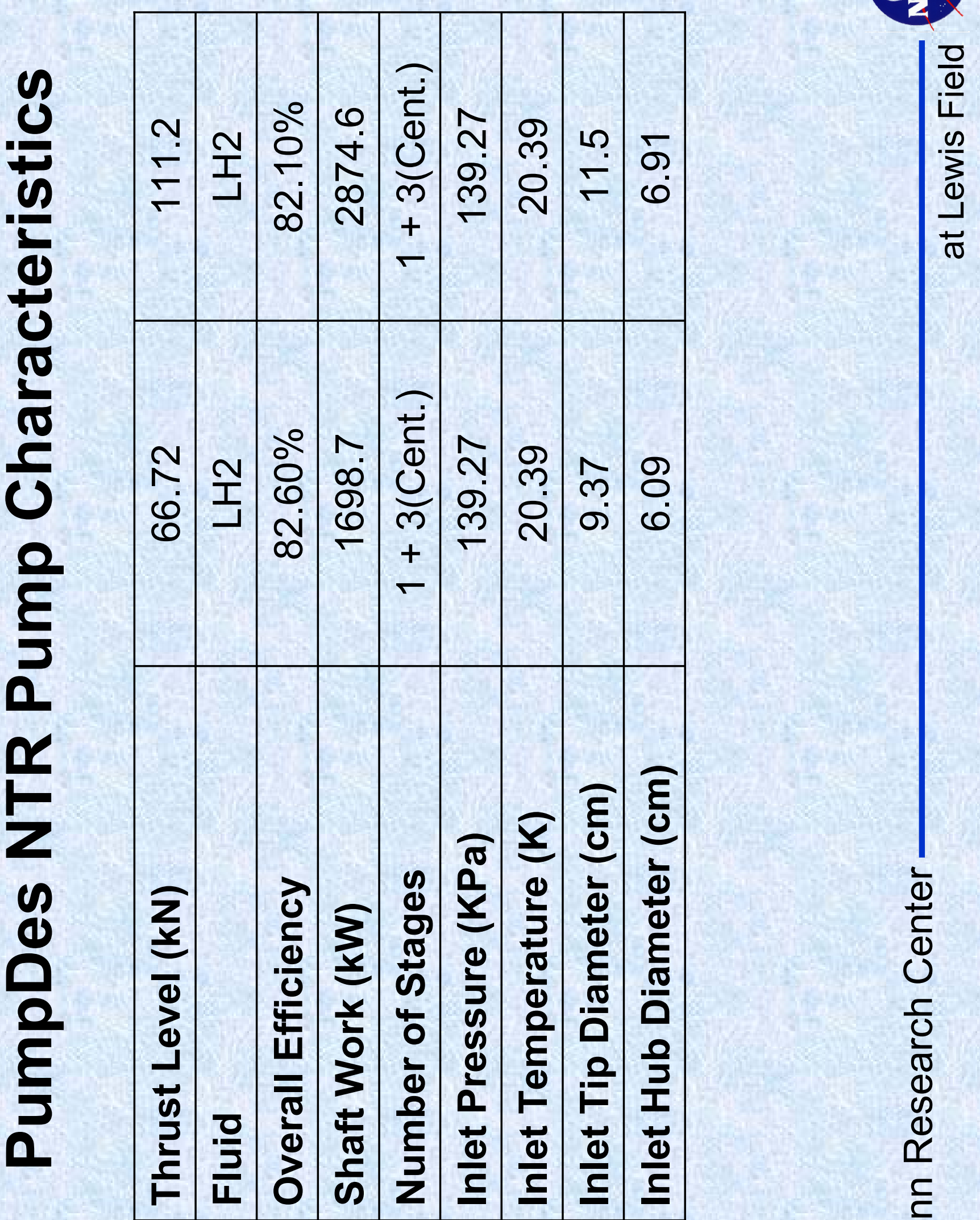


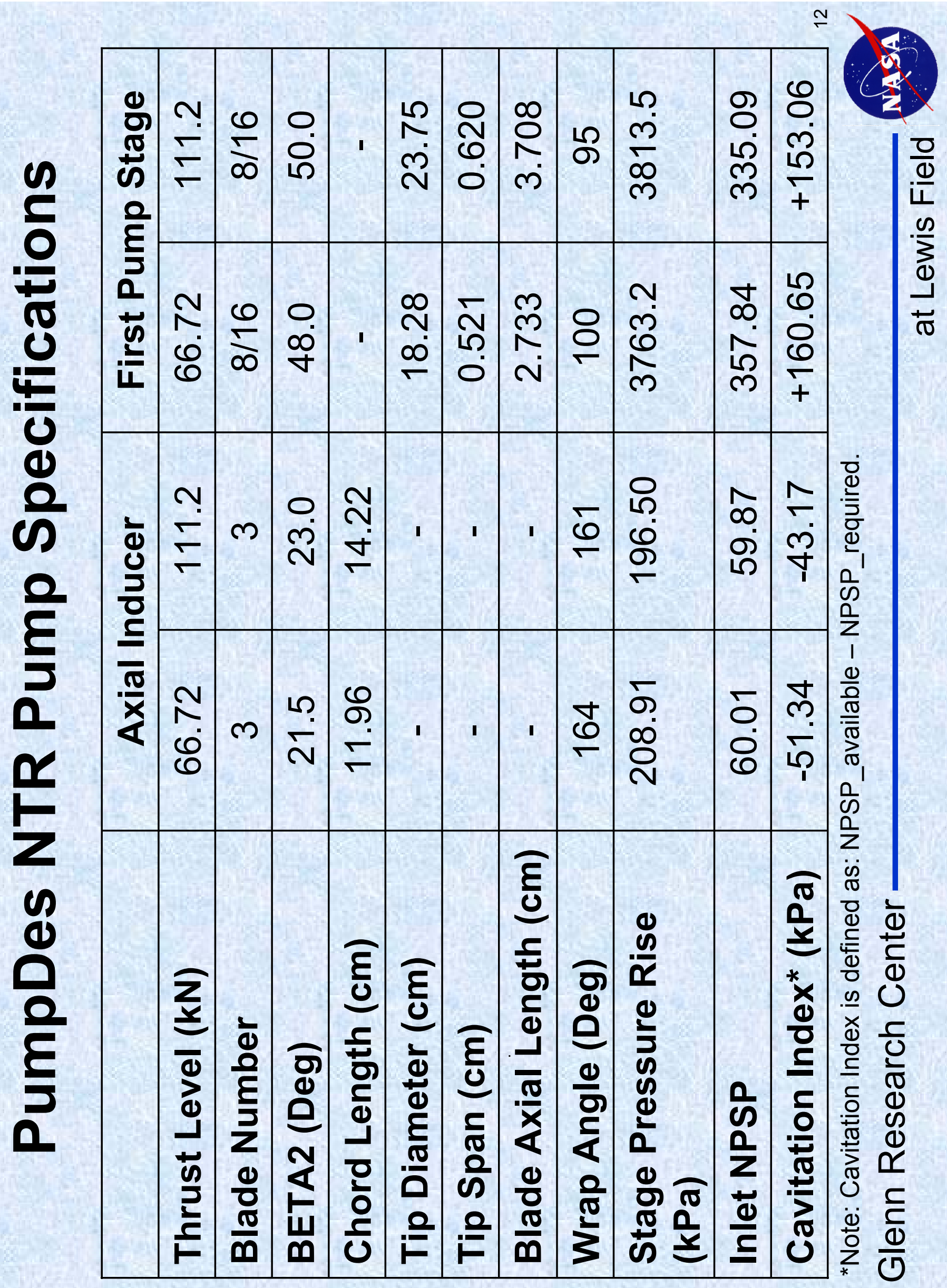




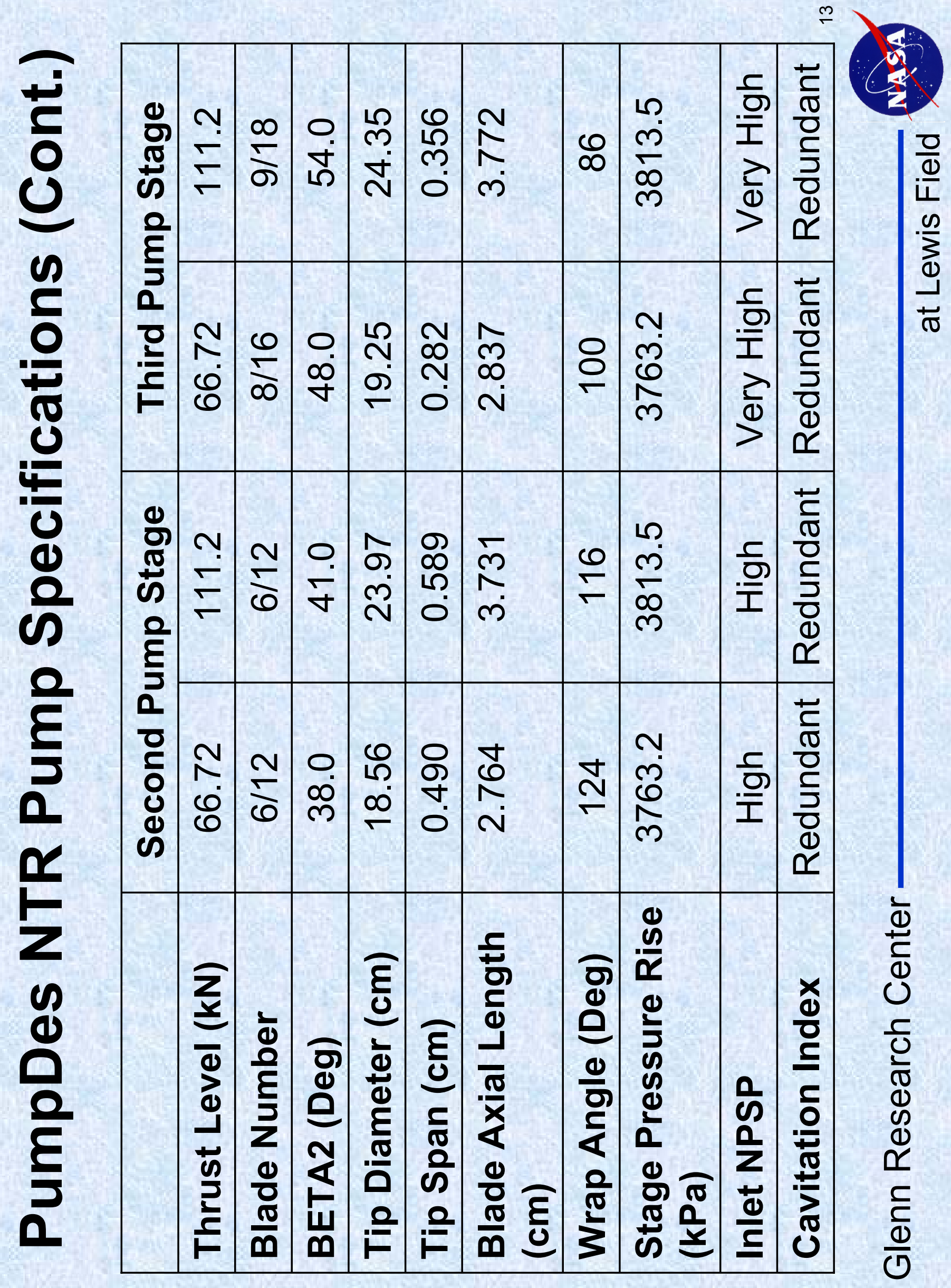


4
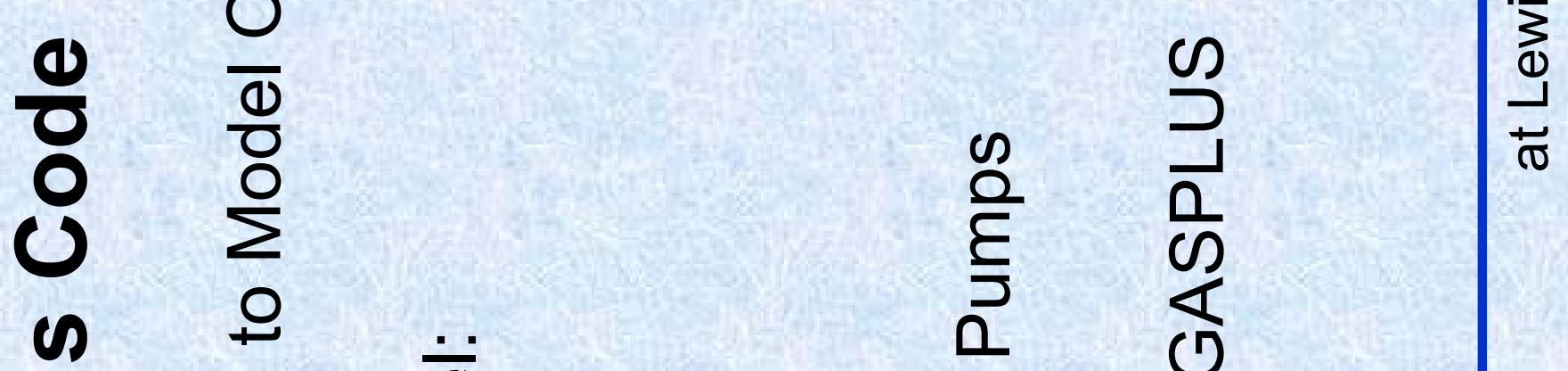

웅

(1)

$\frac{1}{2}$

$\begin{array}{ll}0 & \frac{1}{0} \\ \frac{1}{10} & \geq\end{array}$

$10 \quad \sum$

4

(1) है है कै

$\frac{E}{2}$

1
0
0
0
0

O E क U

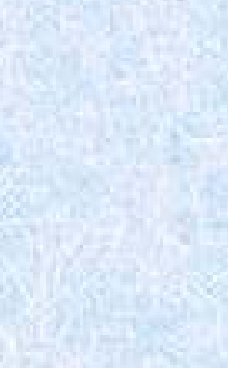

5

ค

4

ค

$\geq$

$\infty$

(

은 $\frac{\bar{d}}{0}$

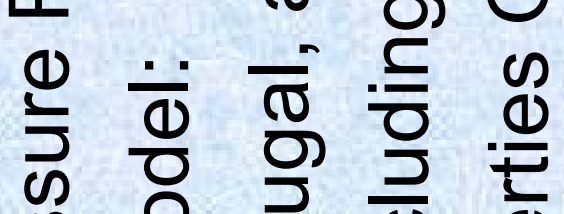

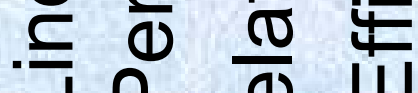

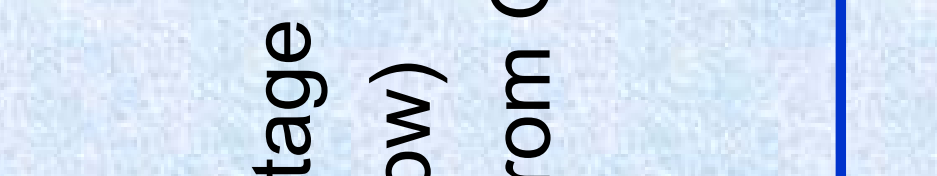

는

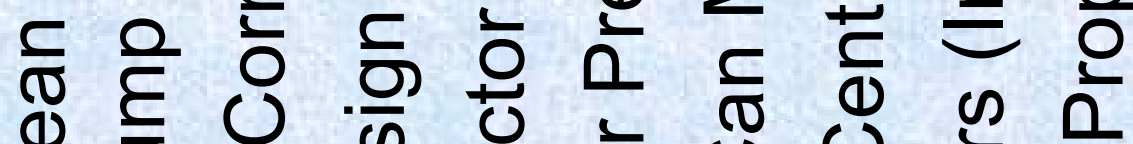

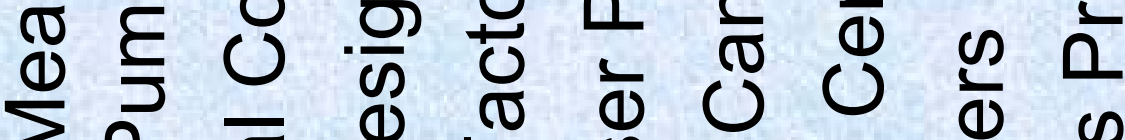

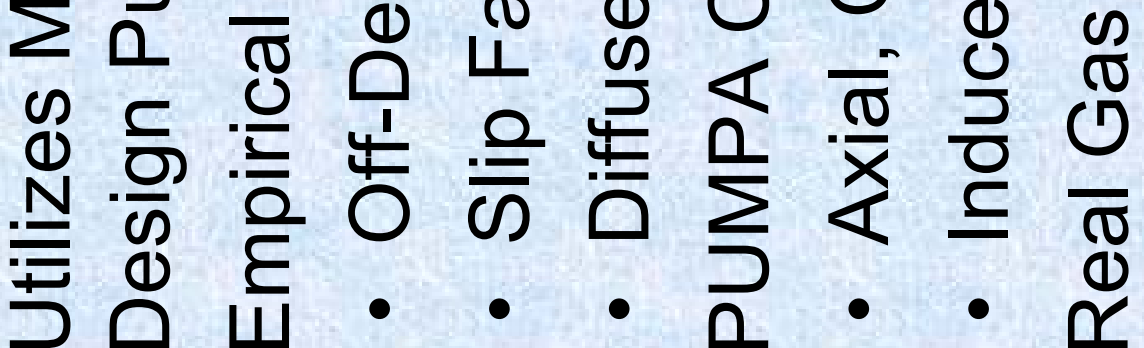



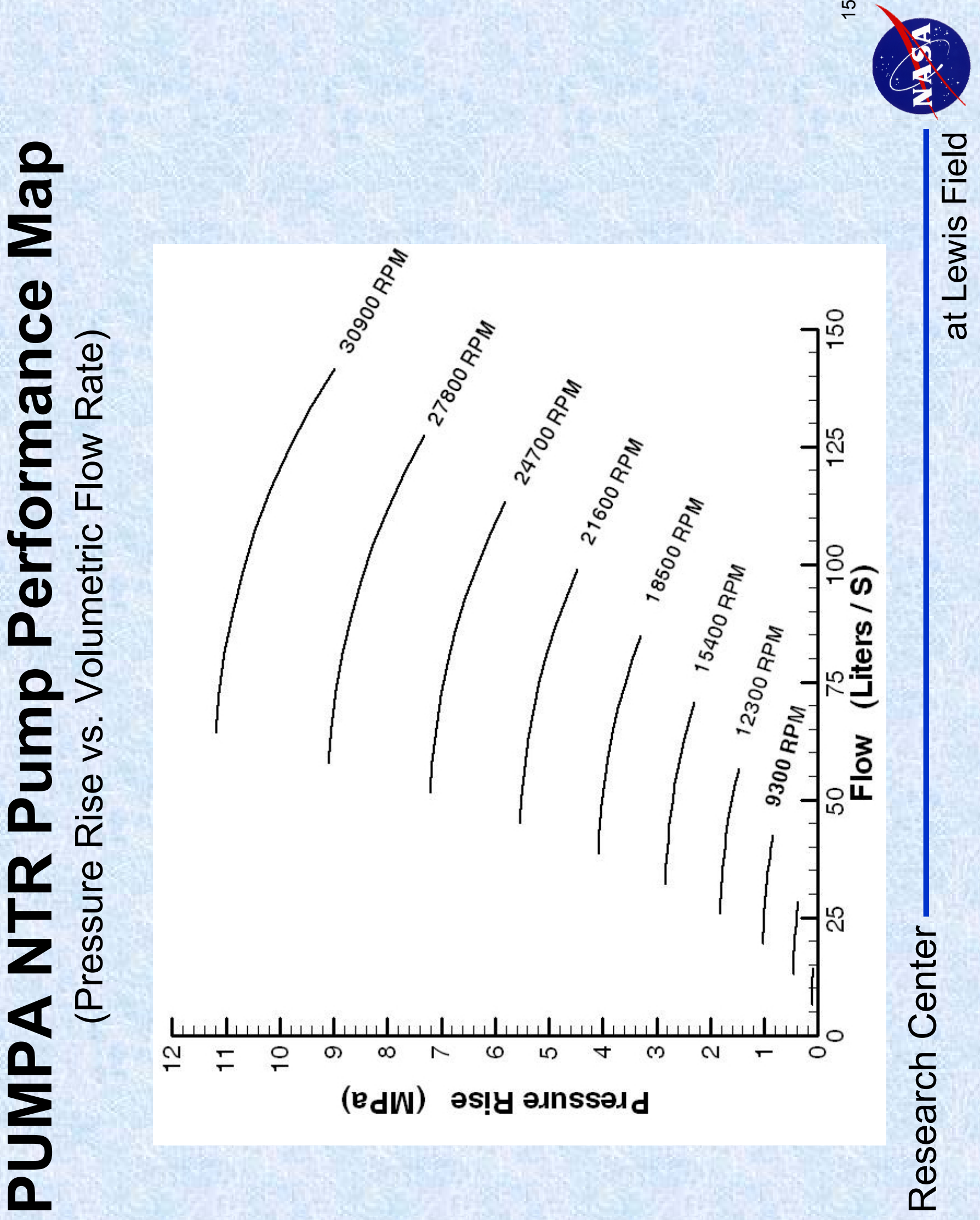

口. 


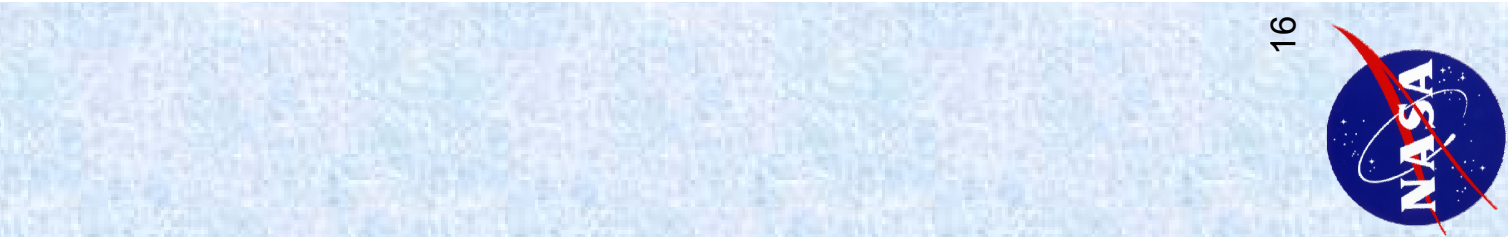

ㅇ.

$10 \%$

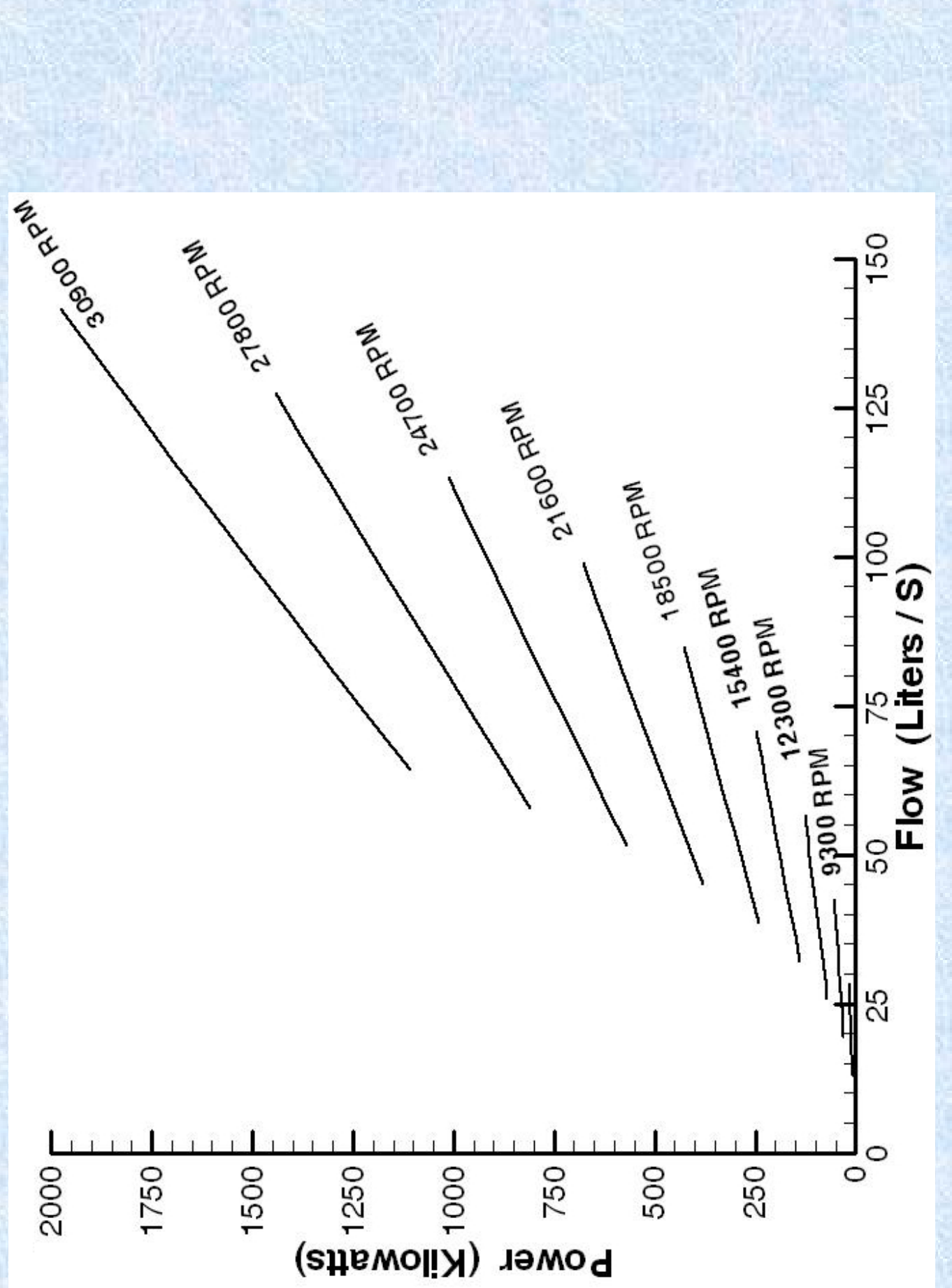

() $\stackrel{2}{\sim}$

(2) 은

(1) 0

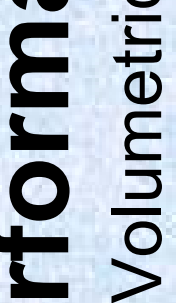

(1)

르 음

(1)

$0 \sum^{2}$

$z^{2}$

$\frac{1}{5}$

口 


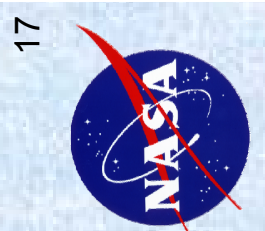

0
0
0

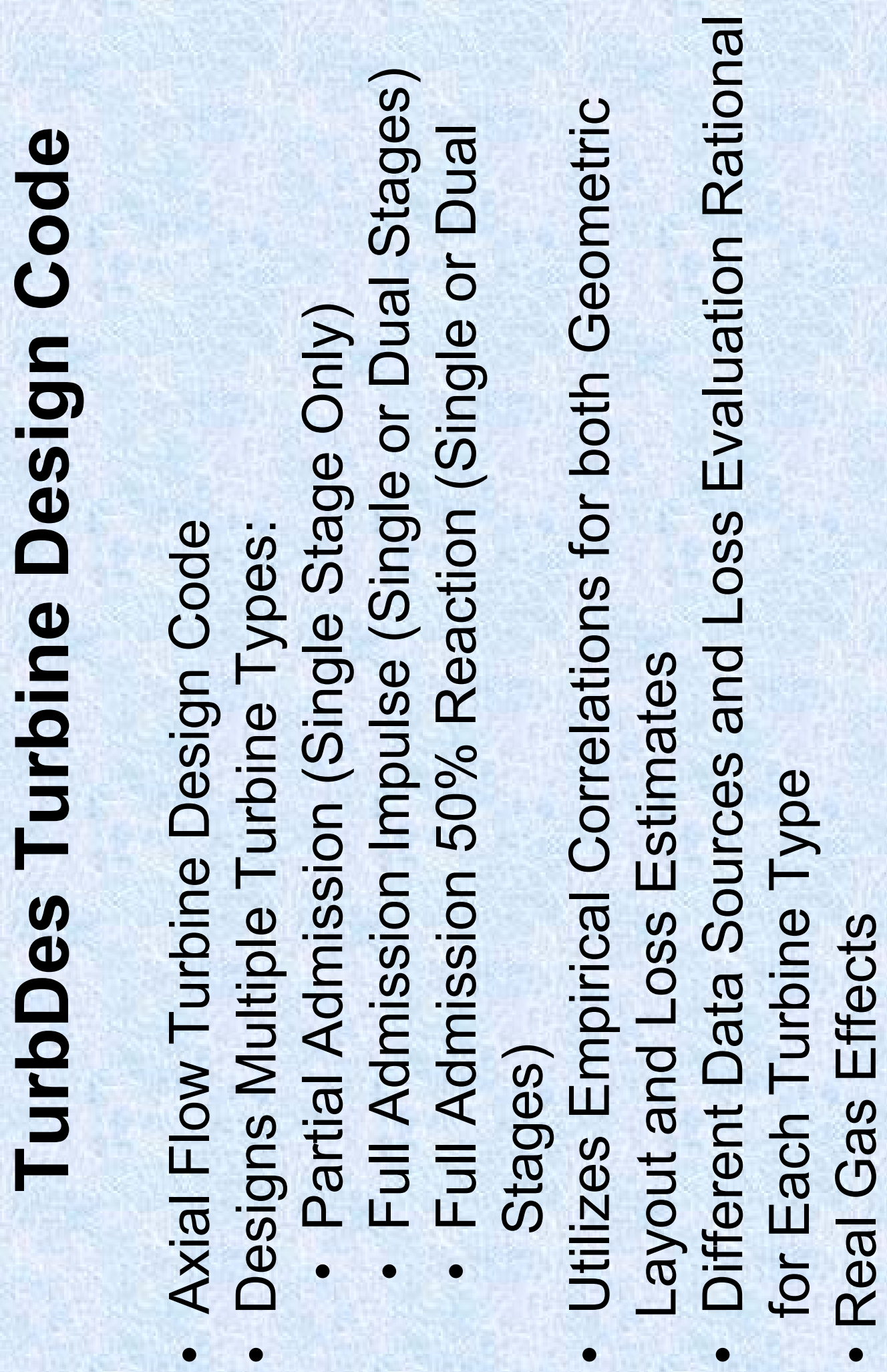




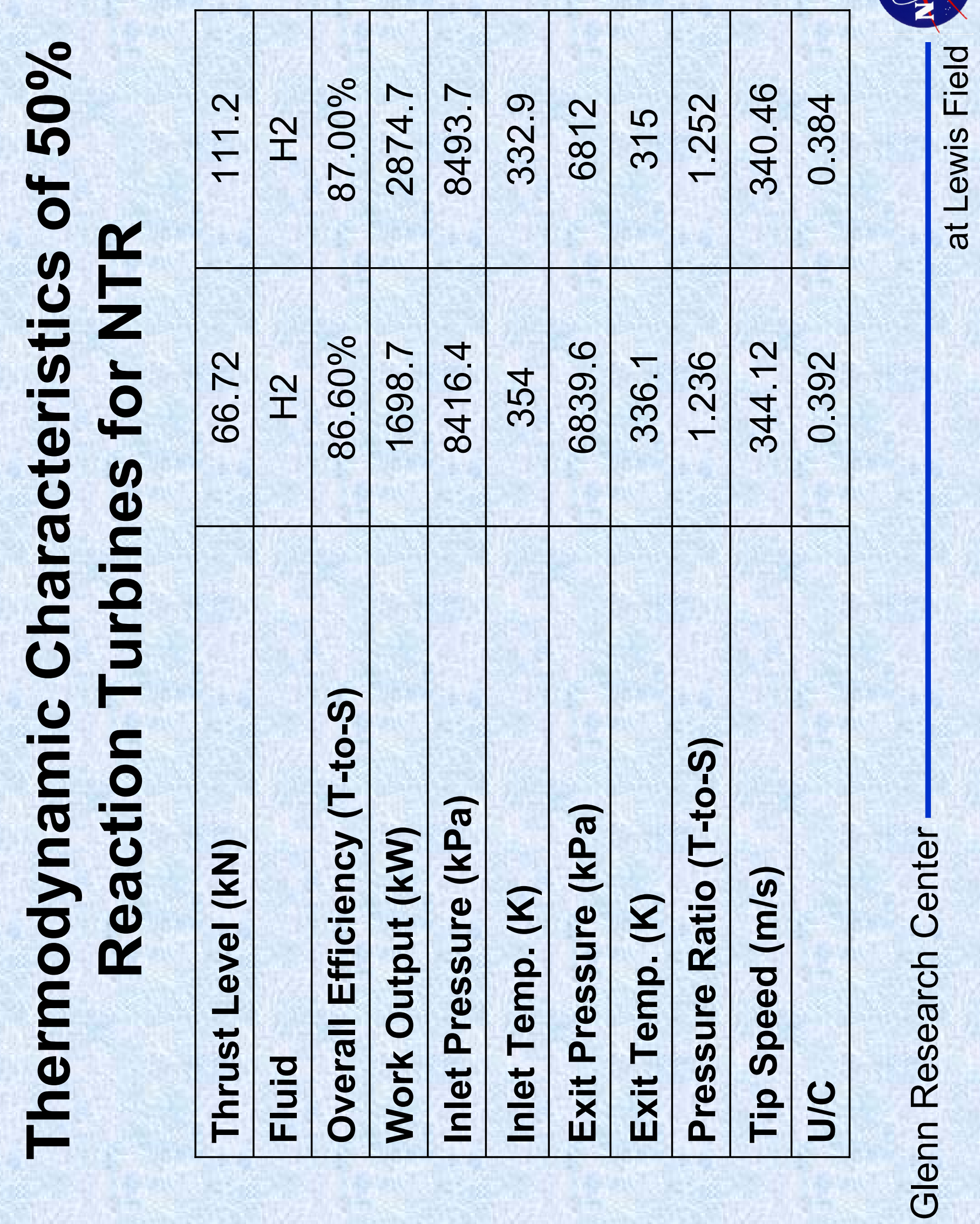




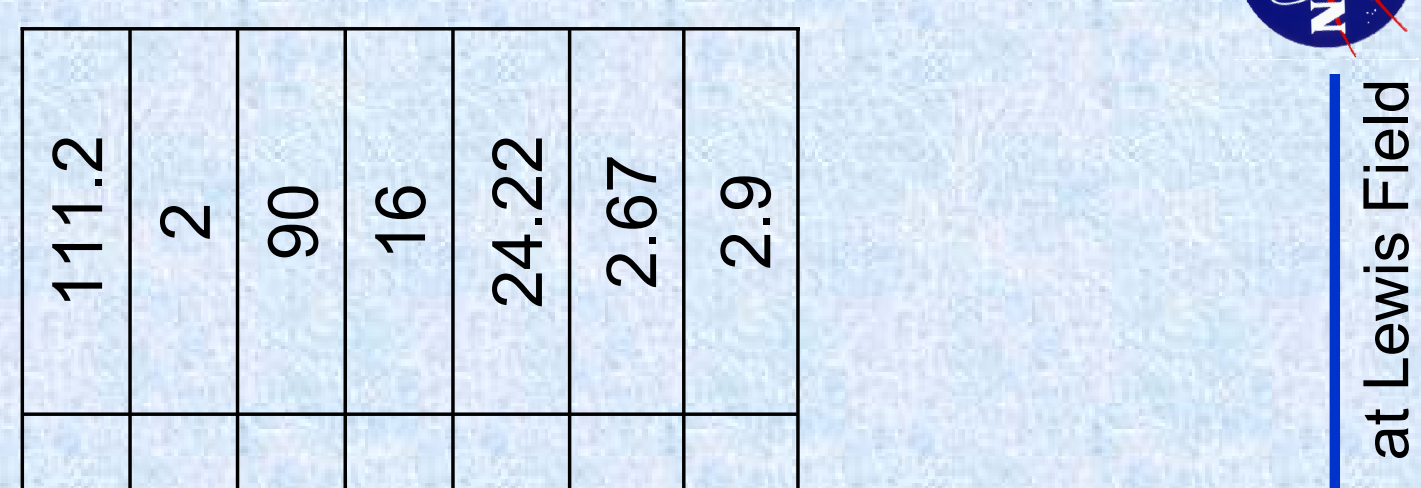

$0_{1}^{0}$

4

$\int_{i=1}^{\infty}$

d 18

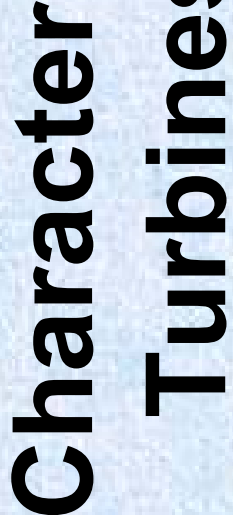

10

(1)

$E$

0

()

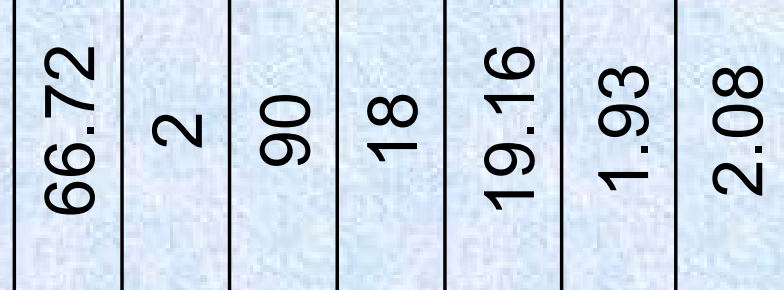



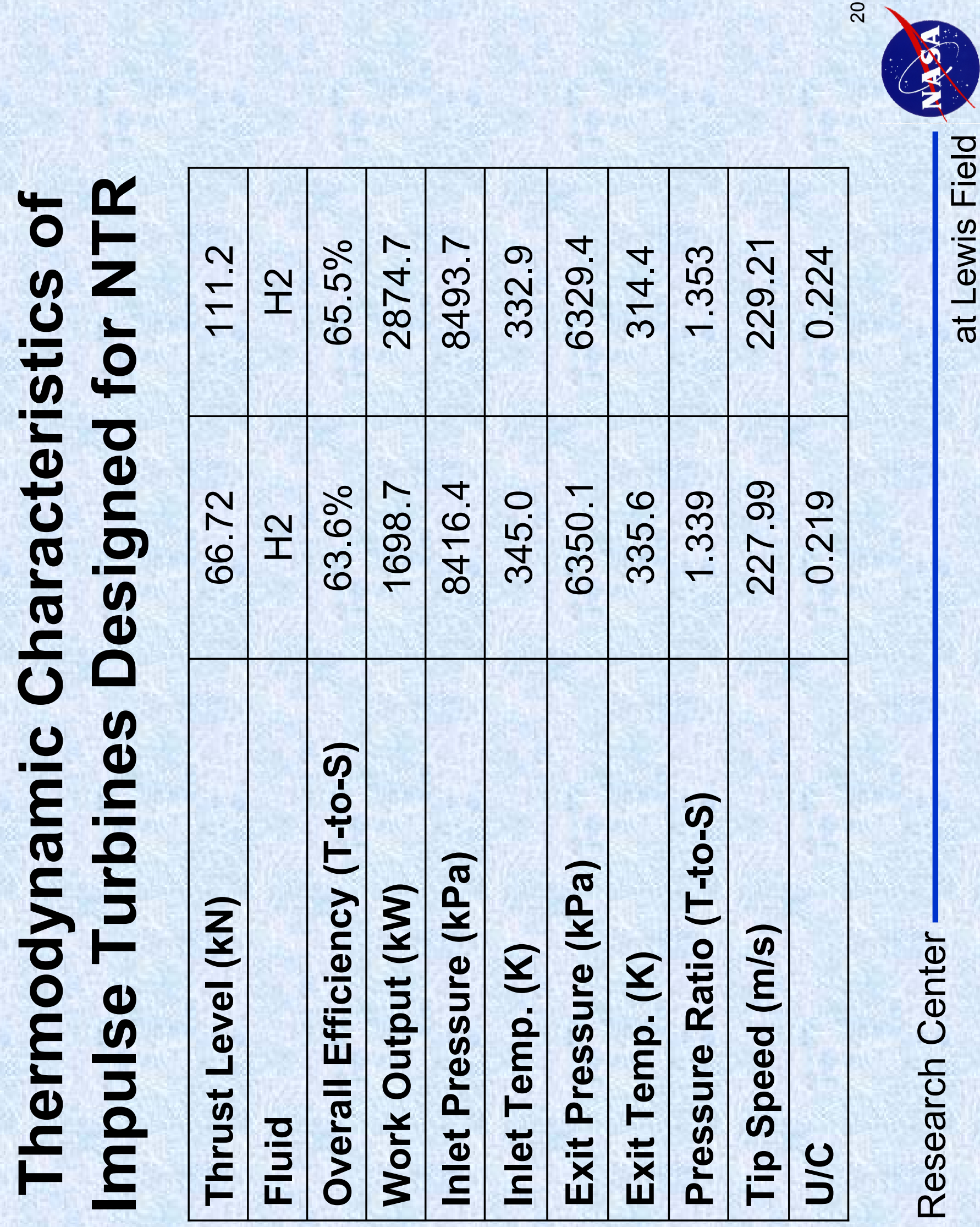

$\frac{\frac{\sigma}{0}}{\frac{1}{1}}$

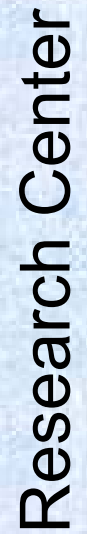


올

号

- 2

(1) 4

는

느

홀

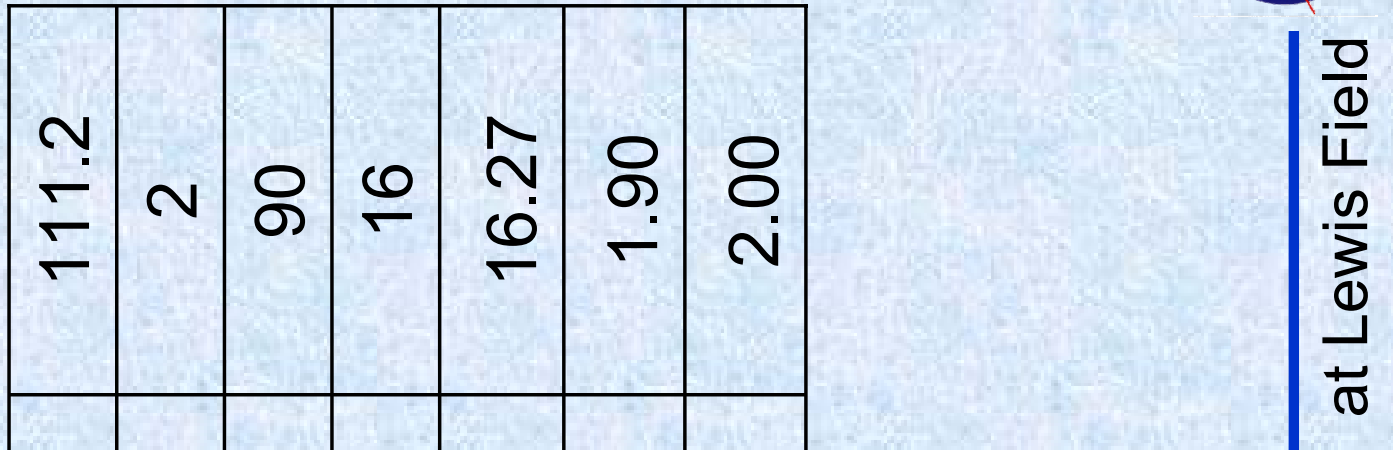

$\frac{\bar{\Phi}}{\frac{1}{2}}$

0

은

(1)

d)

$\square$

$\frac{\frac{5}{0}}{0}$ 


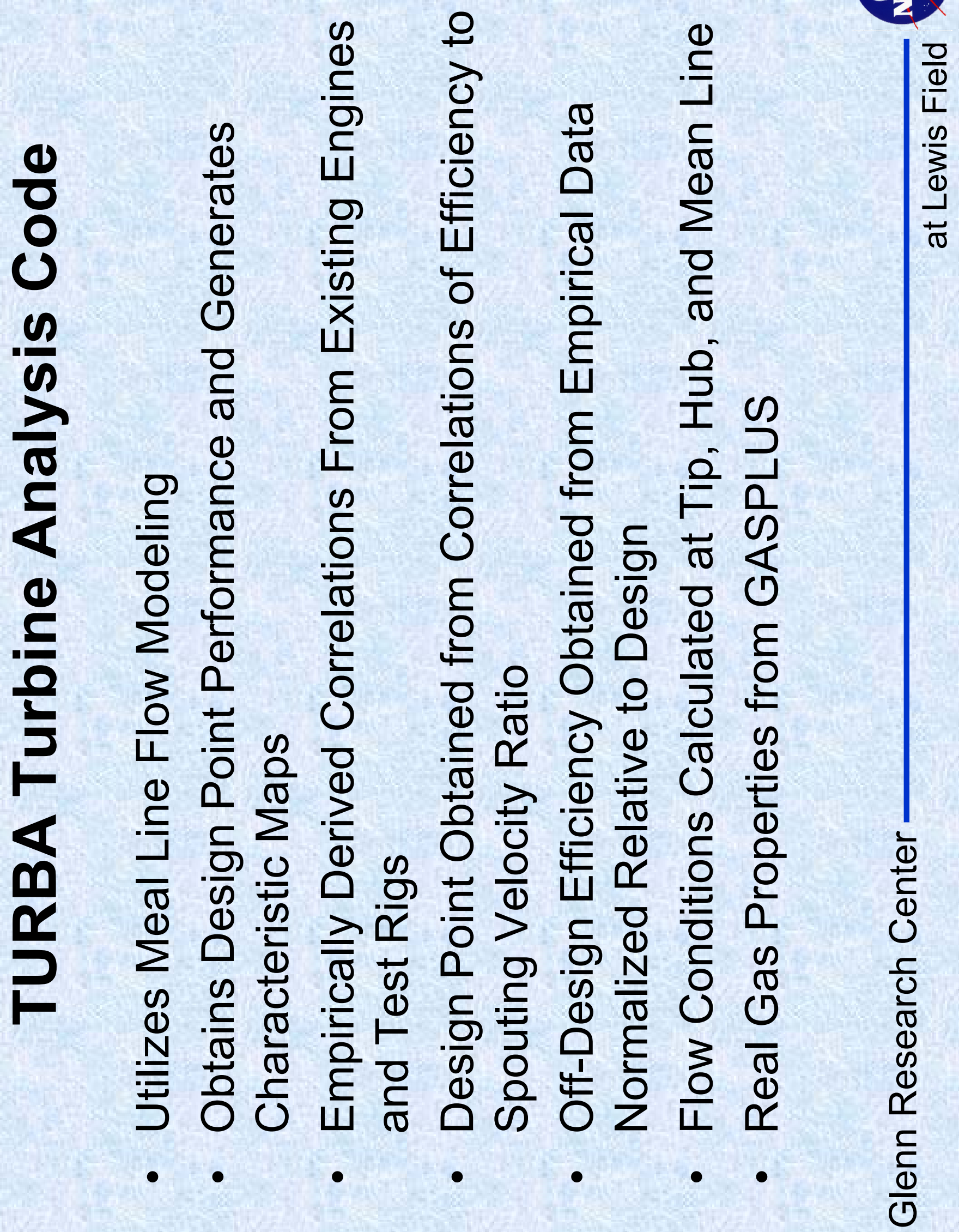

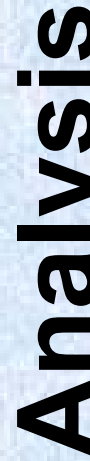



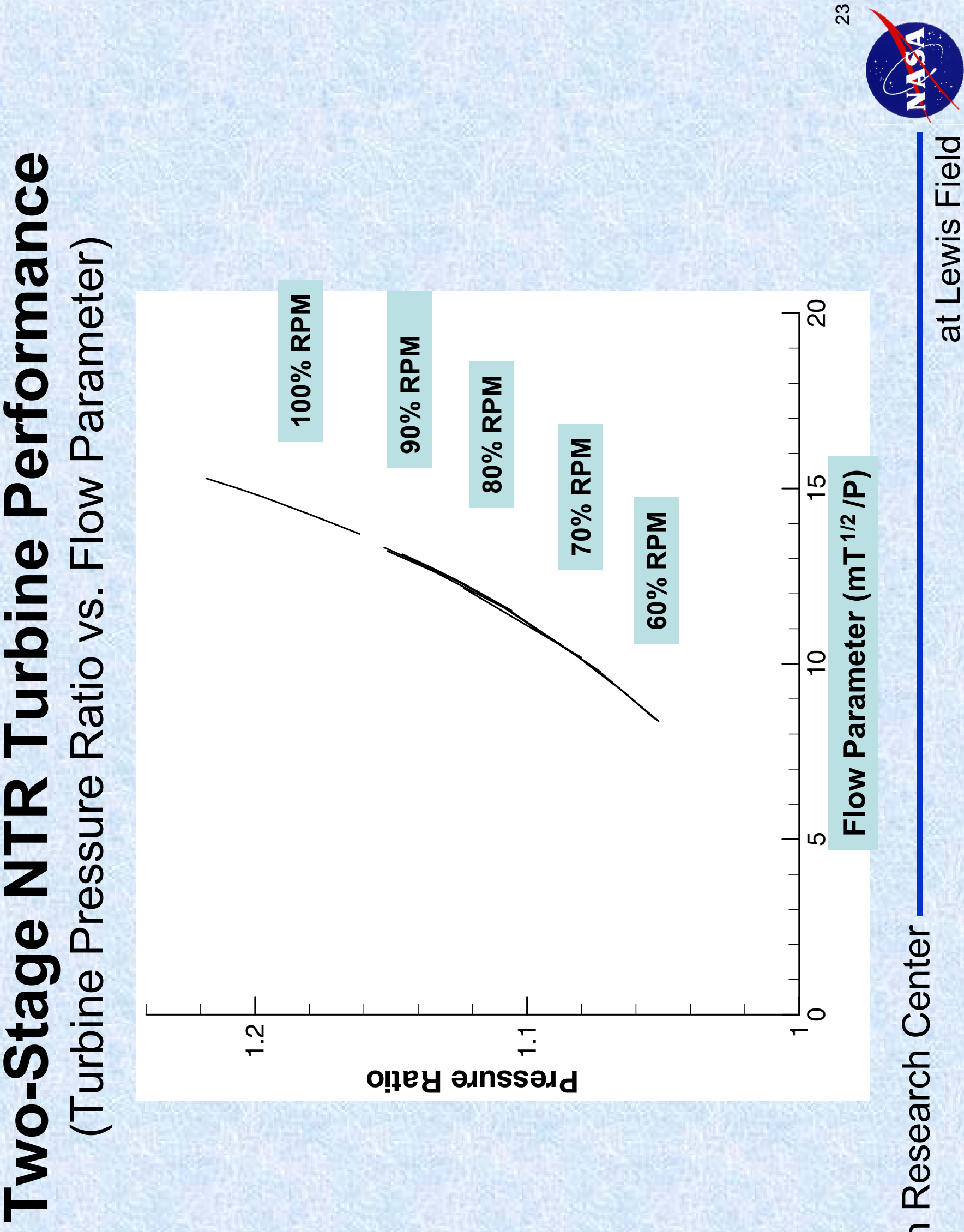
15

(b) $\frac{0}{\pi}$

ह

है

$4 \frac{0}{0}$

(1) 음

a.

(1) ㅇำ

\&

1 वे

$2 \frac{\frac{\Phi}{0}}{2}$

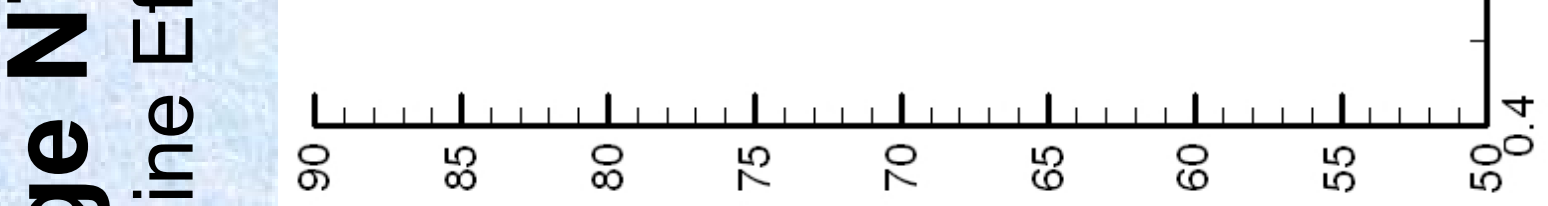

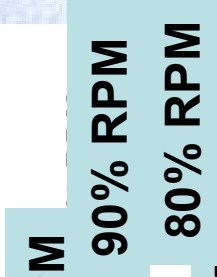

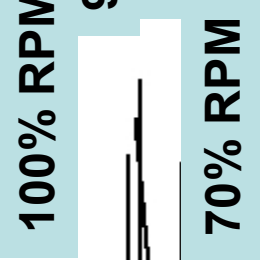

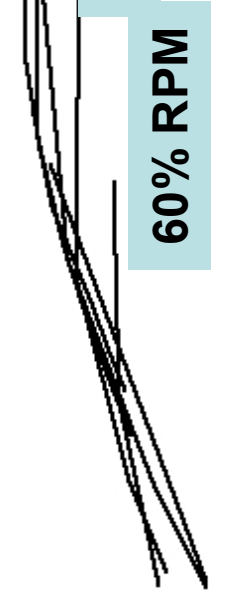

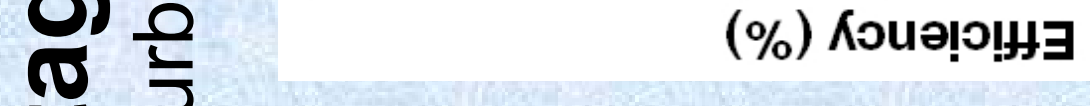

d

0

3 


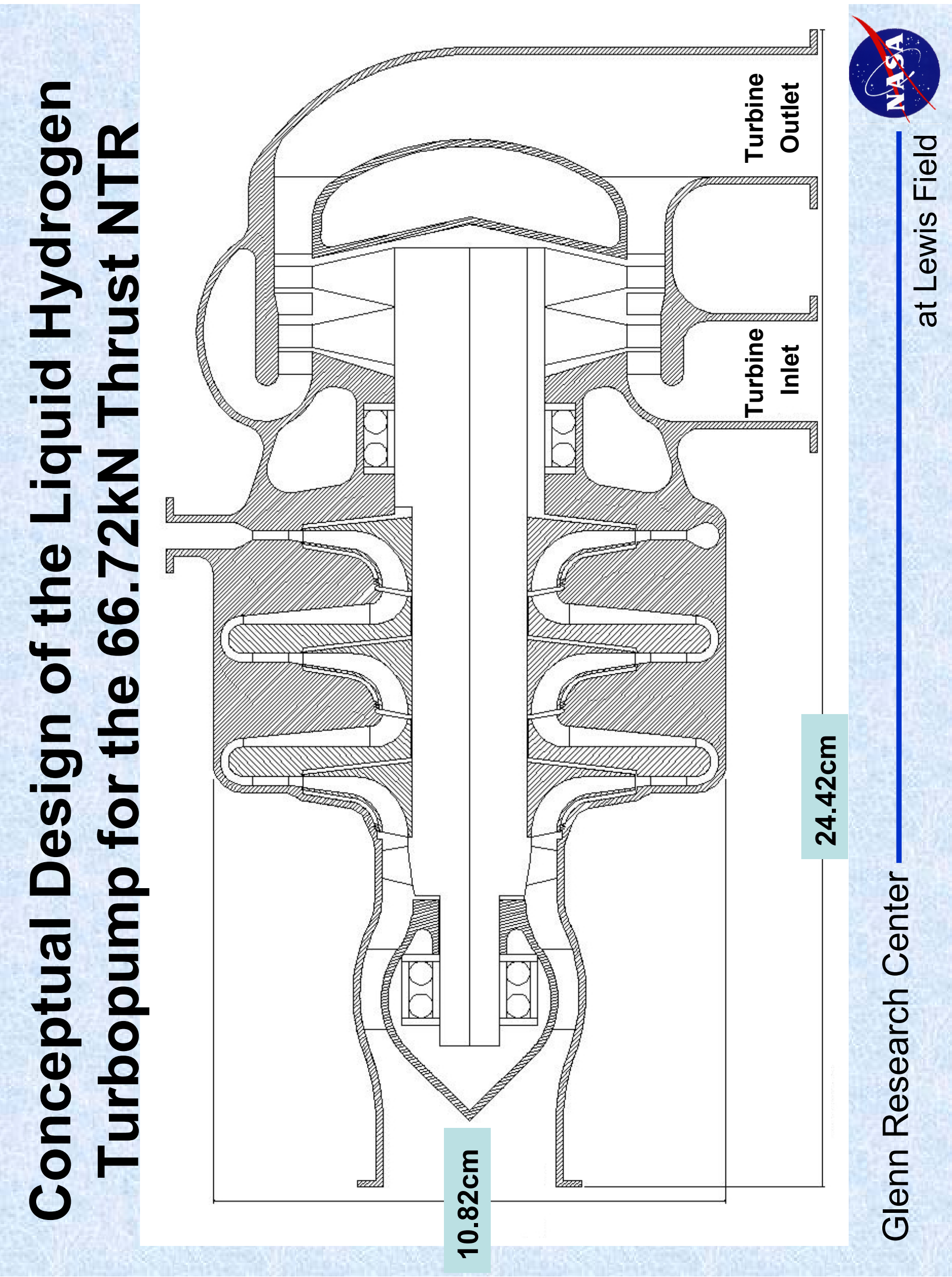


$\frac{c}{c}$

20

$\frac{1}{\frac{1}{2}}$

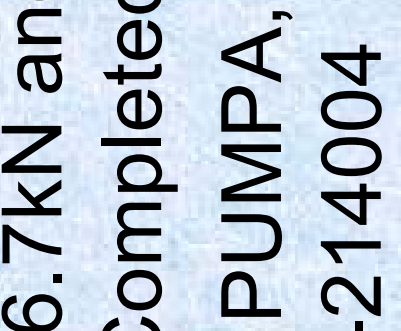

$\frac{\frac{0}{0}}{\frac{1}{4}}$

10

$\frac{1}{\pi}$

$\varepsilon$

$\frac{\sigma}{\infty} \frac{\sigma}{\sigma}$

$\frac{0}{10}$

(1) 0

व ह

$\geqslant \quad \frac{\varepsilon}{\sigma}$

10

20

क

읃

0 क

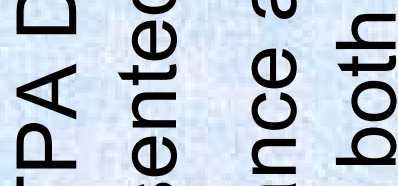

100

क

(1) Ð

$\frac{4}{4}$

$\vdash$ क

$\Upsilon \stackrel{1}{\square}$ 으

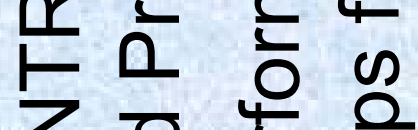

$\sum$ 은

ब

을 는

Uㄷ

产

ᄃ

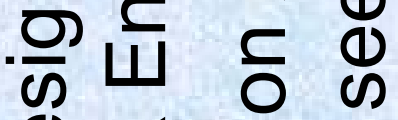

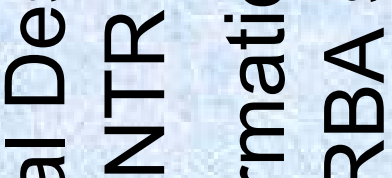

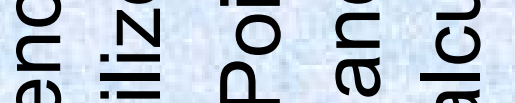

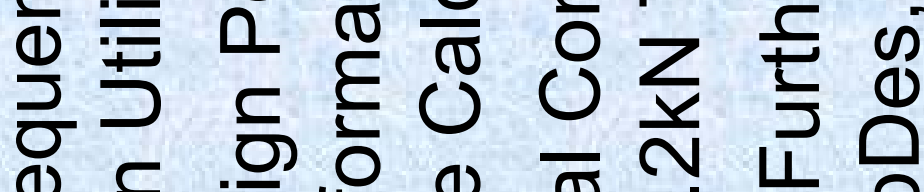

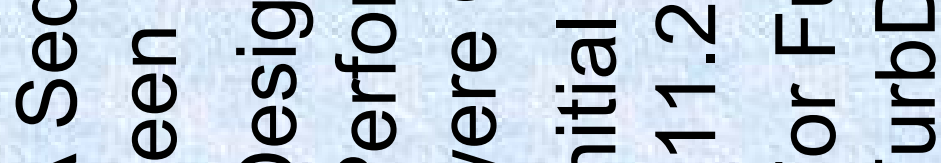

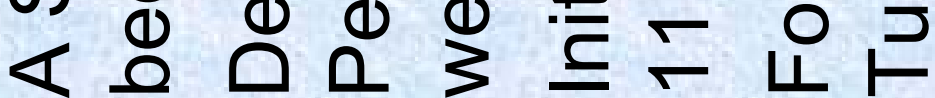




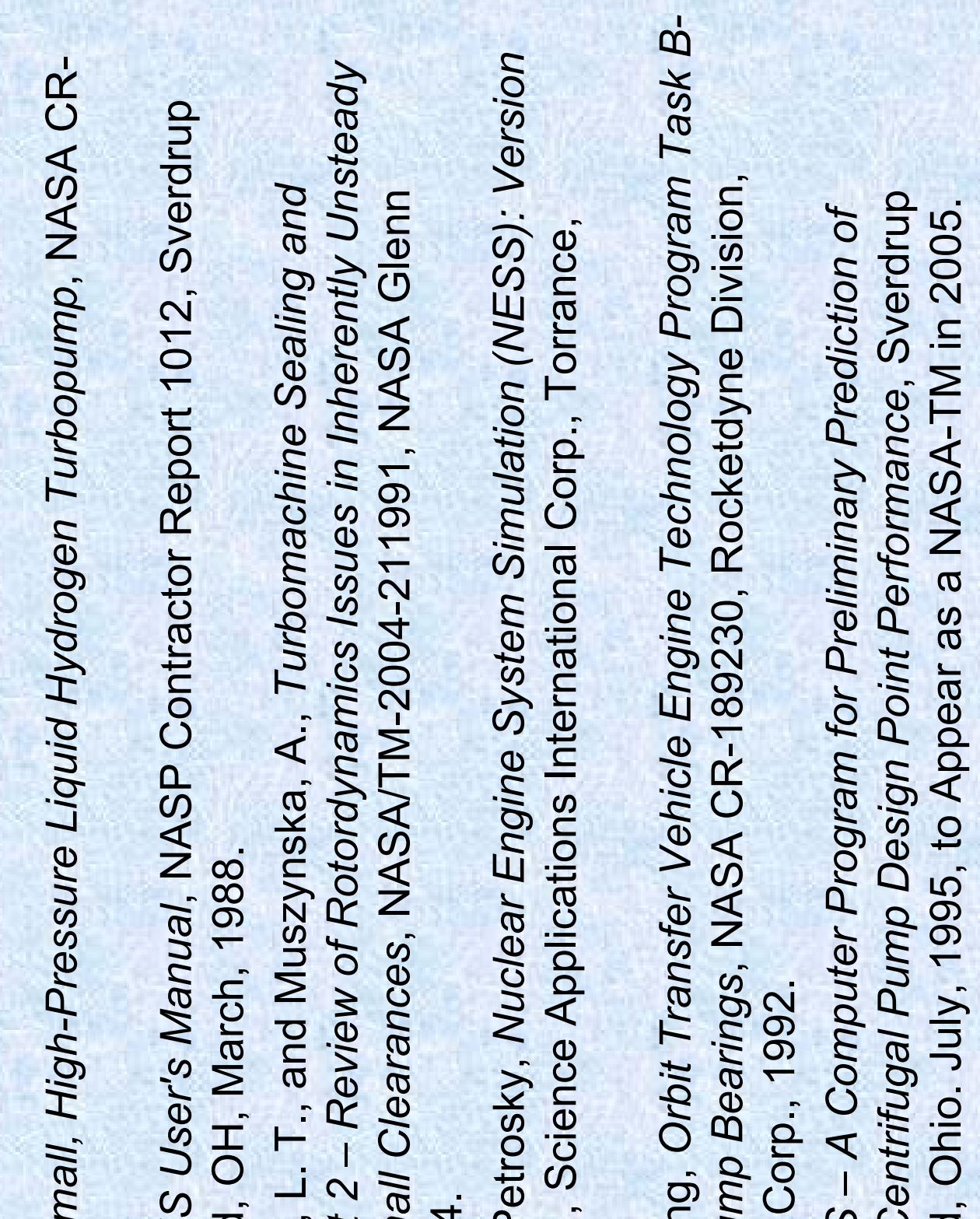

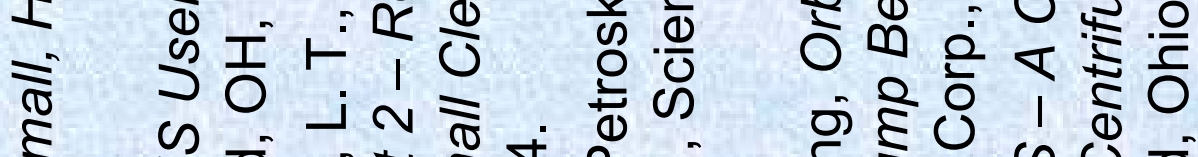

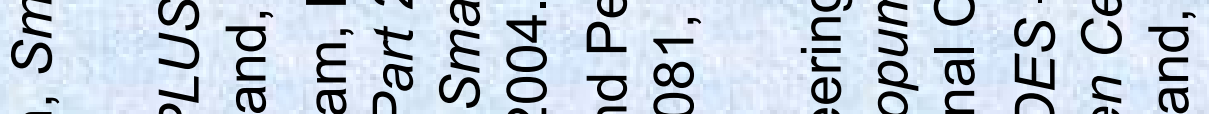

c.

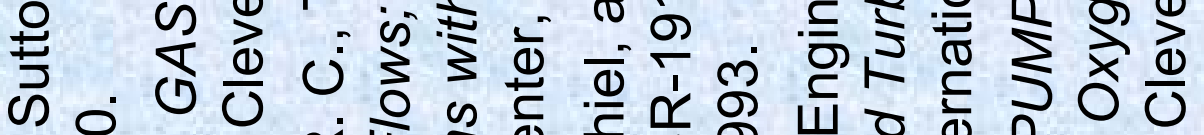

○

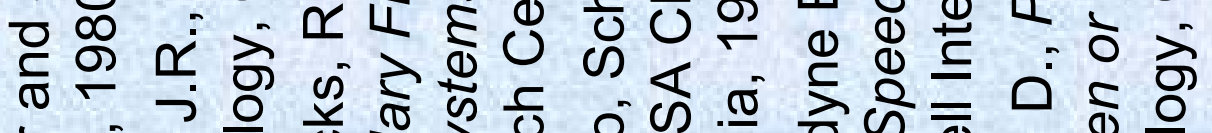
के

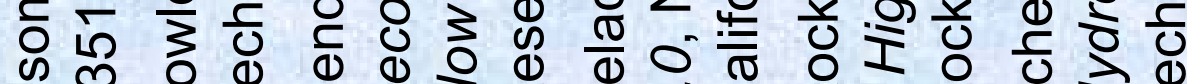
Uั

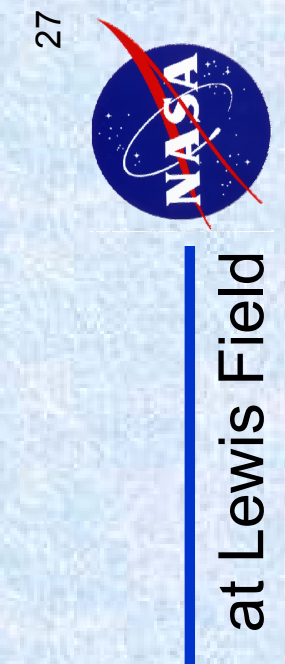




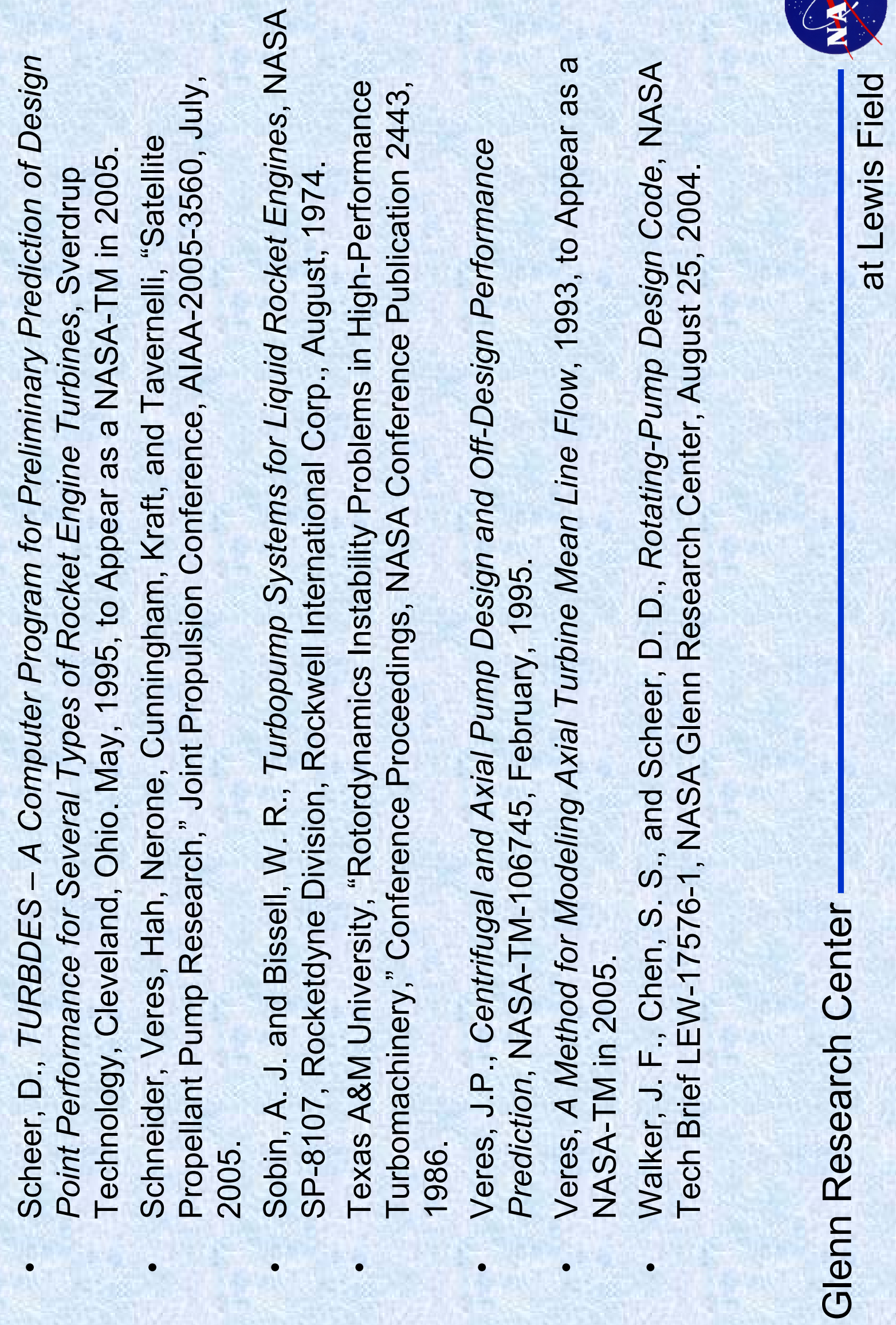




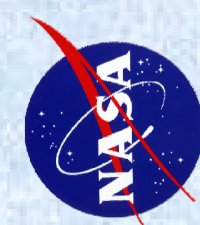

음

Ш

3

$\frac{\frac{n}{4}}{\frac{1}{0}}$

(O)

5

1

90

คด 


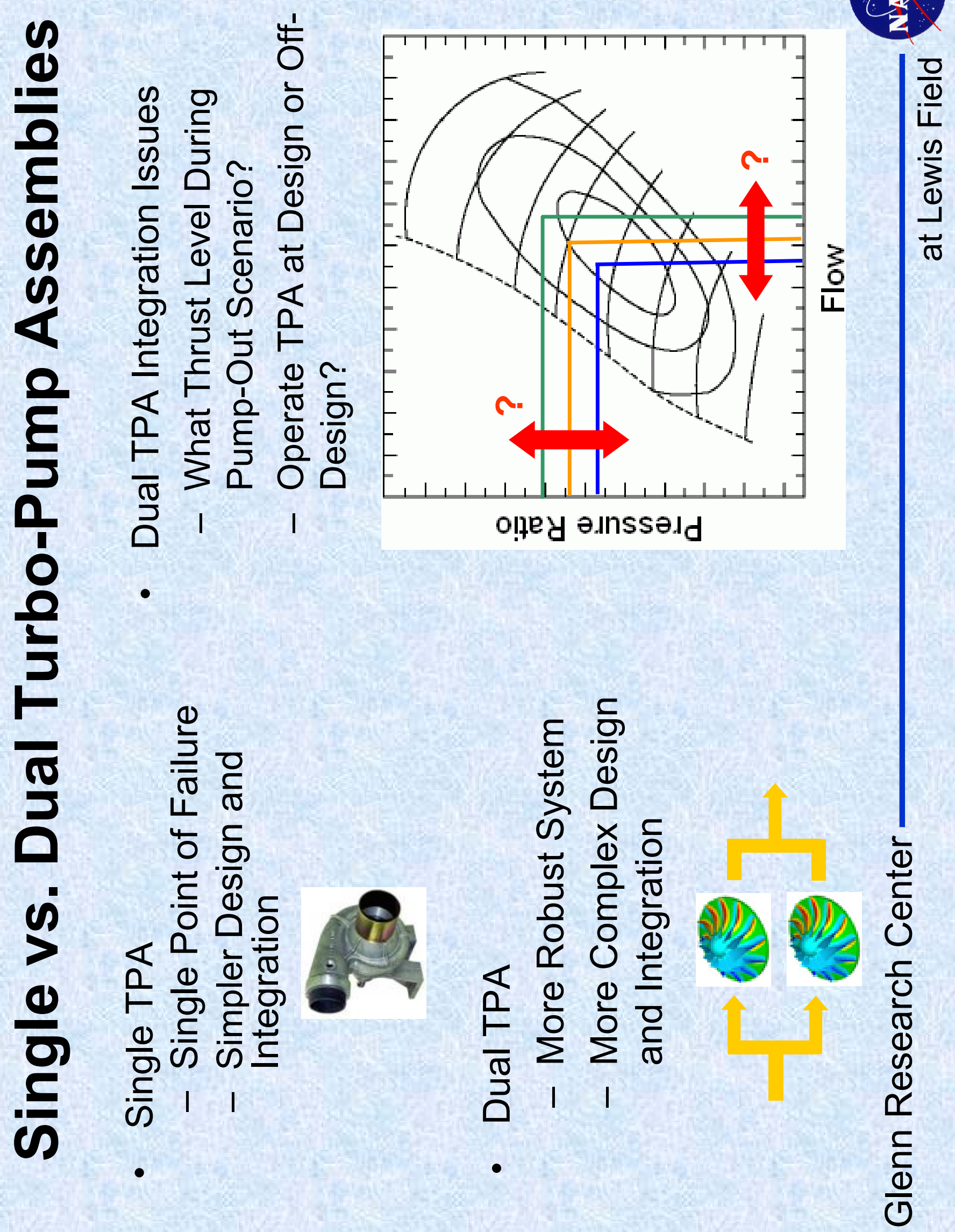




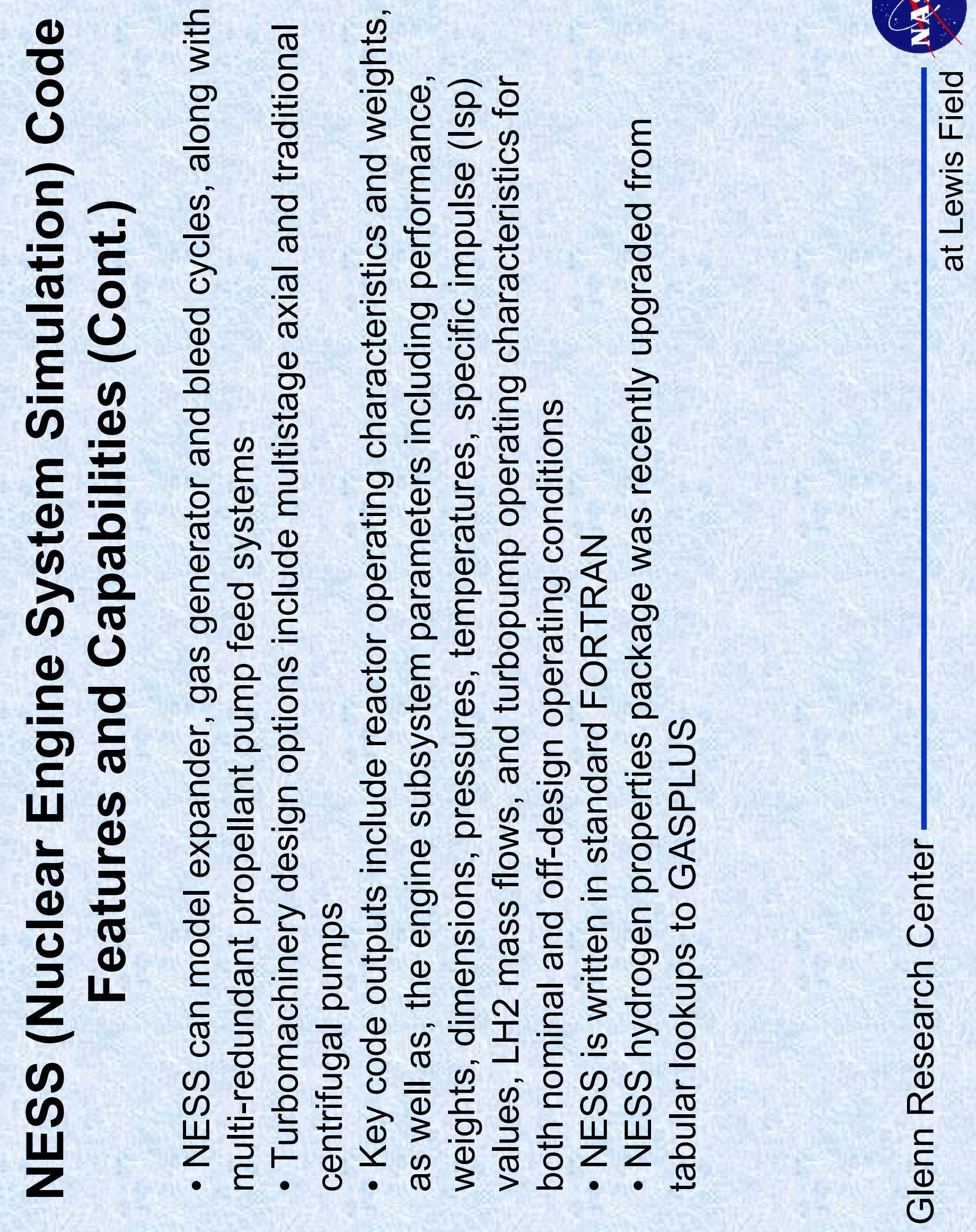




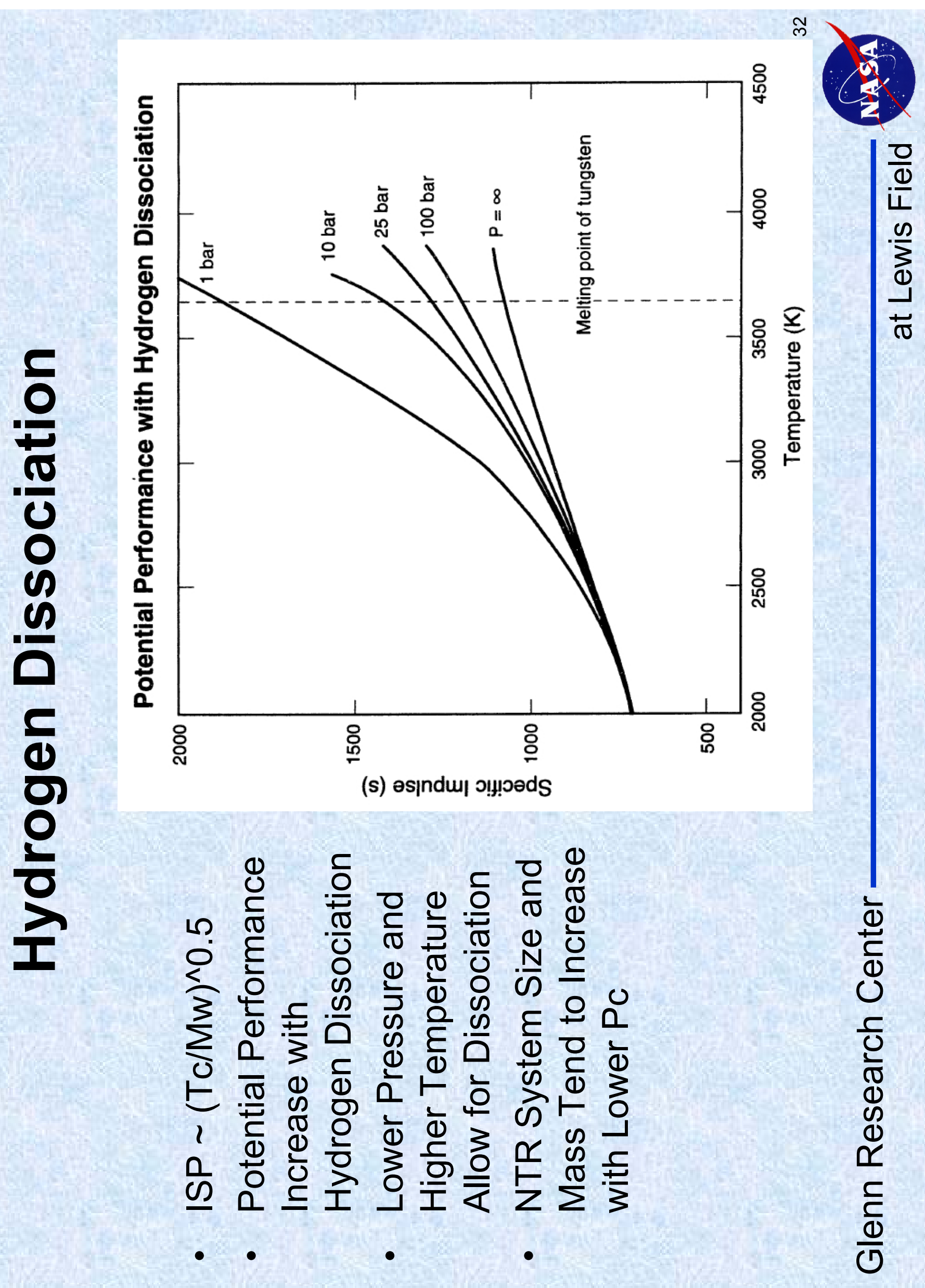




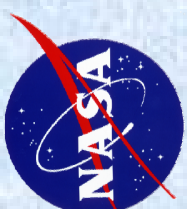

18

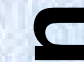

(a)

$\frac{1}{4}$

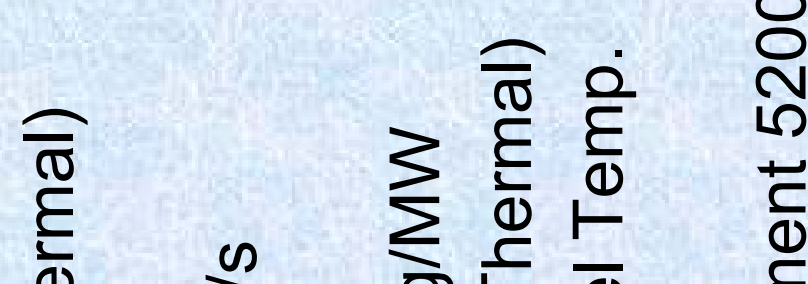

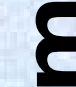

av

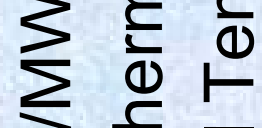

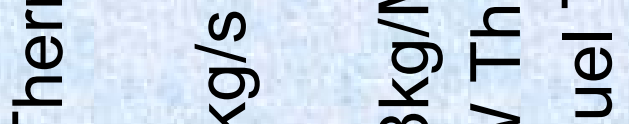

동

$\geqslant \quad$ N

$\sum \quad$

$\sum_{0} \frac{F}{3}$

$\underset{5}{5}$

$\underset{+}{\pi} \geq$

(1)

ह

(O)

0

1

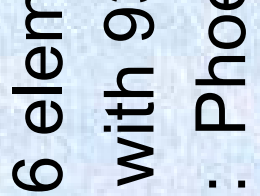

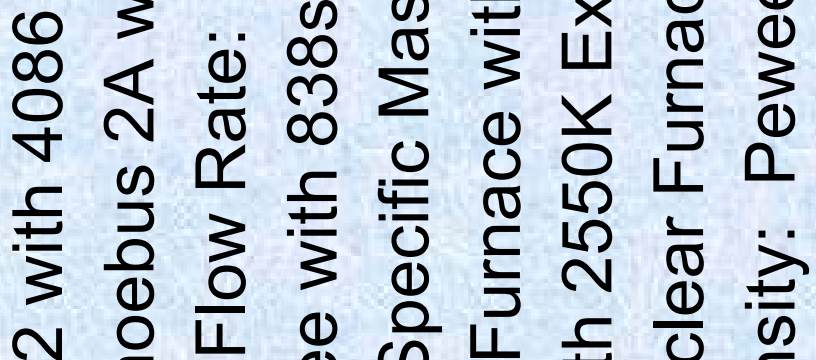

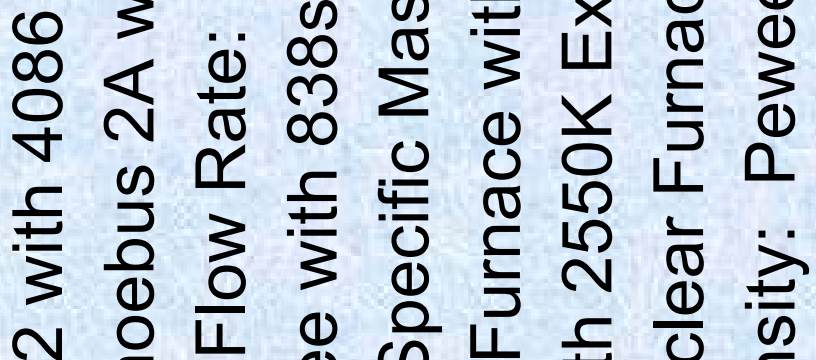

4

0 은

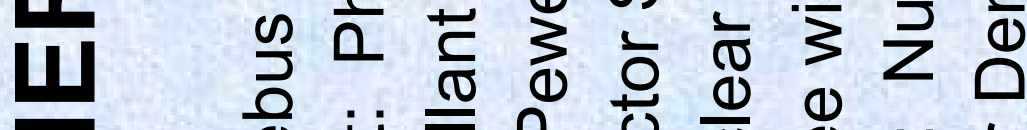

$\frac{2}{2}$

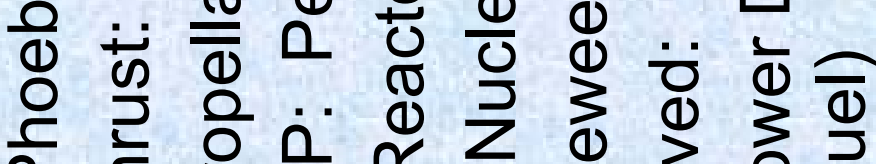

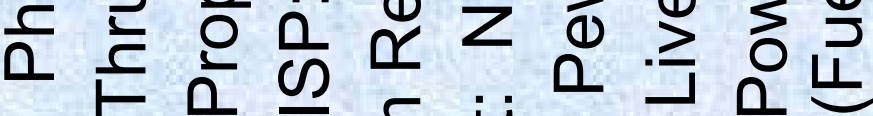

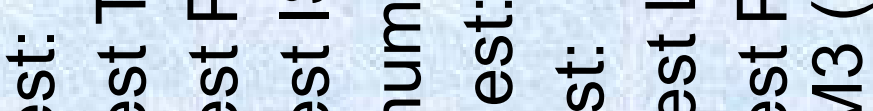

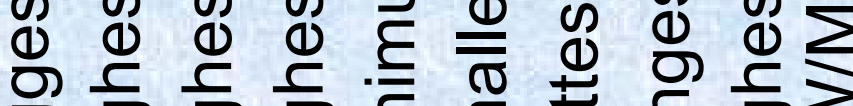

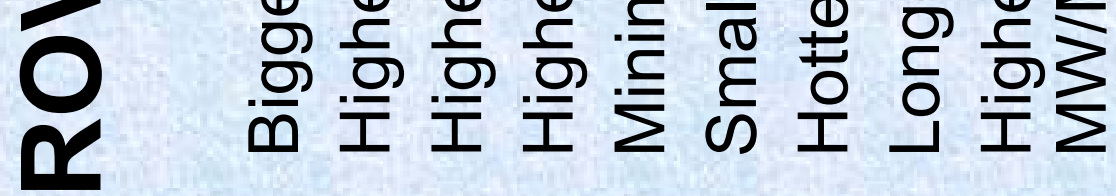

$\propto$ 


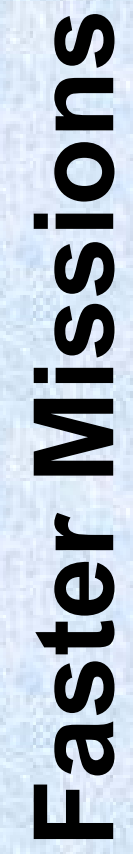

$\frac{0}{0}$
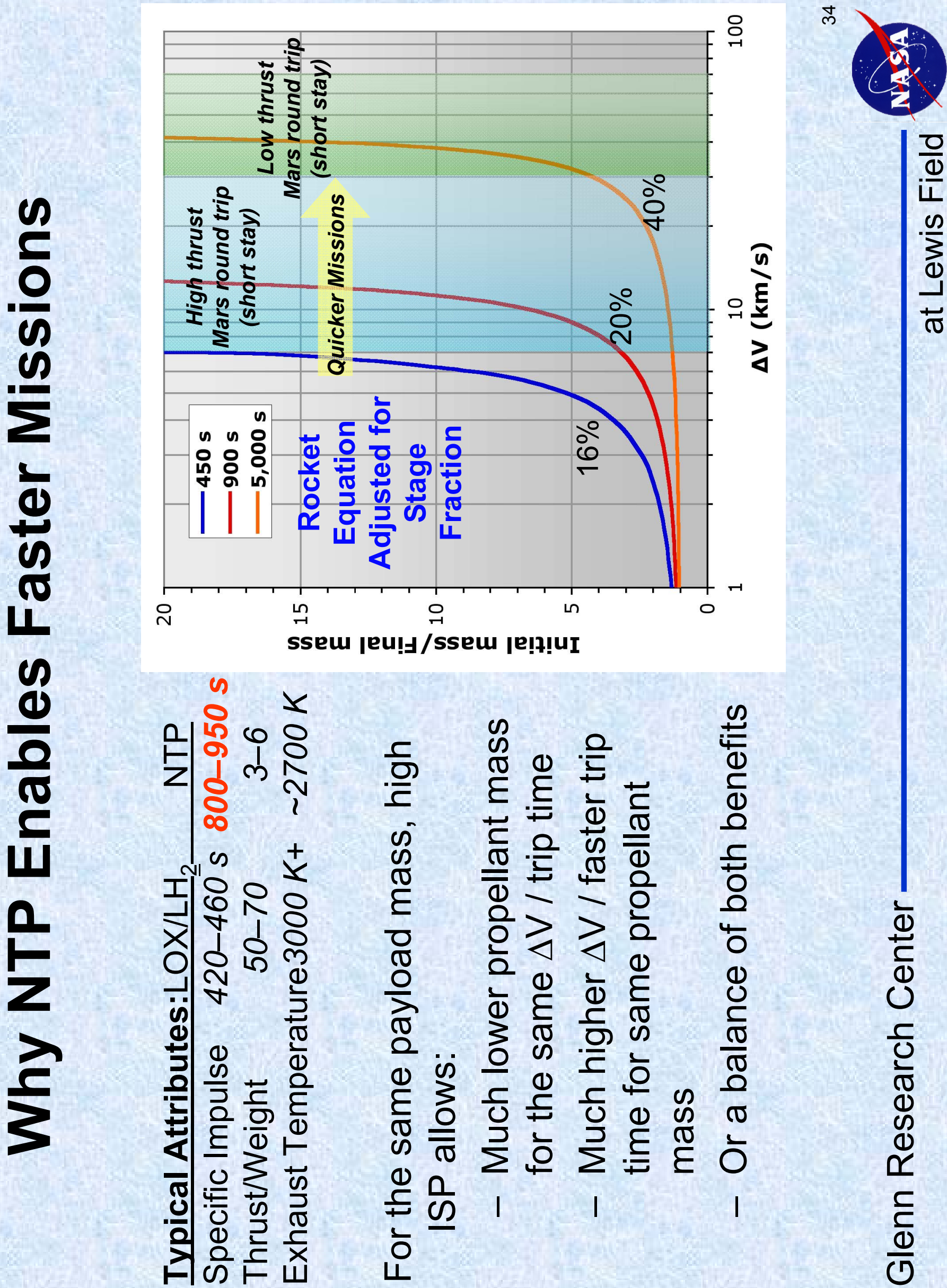


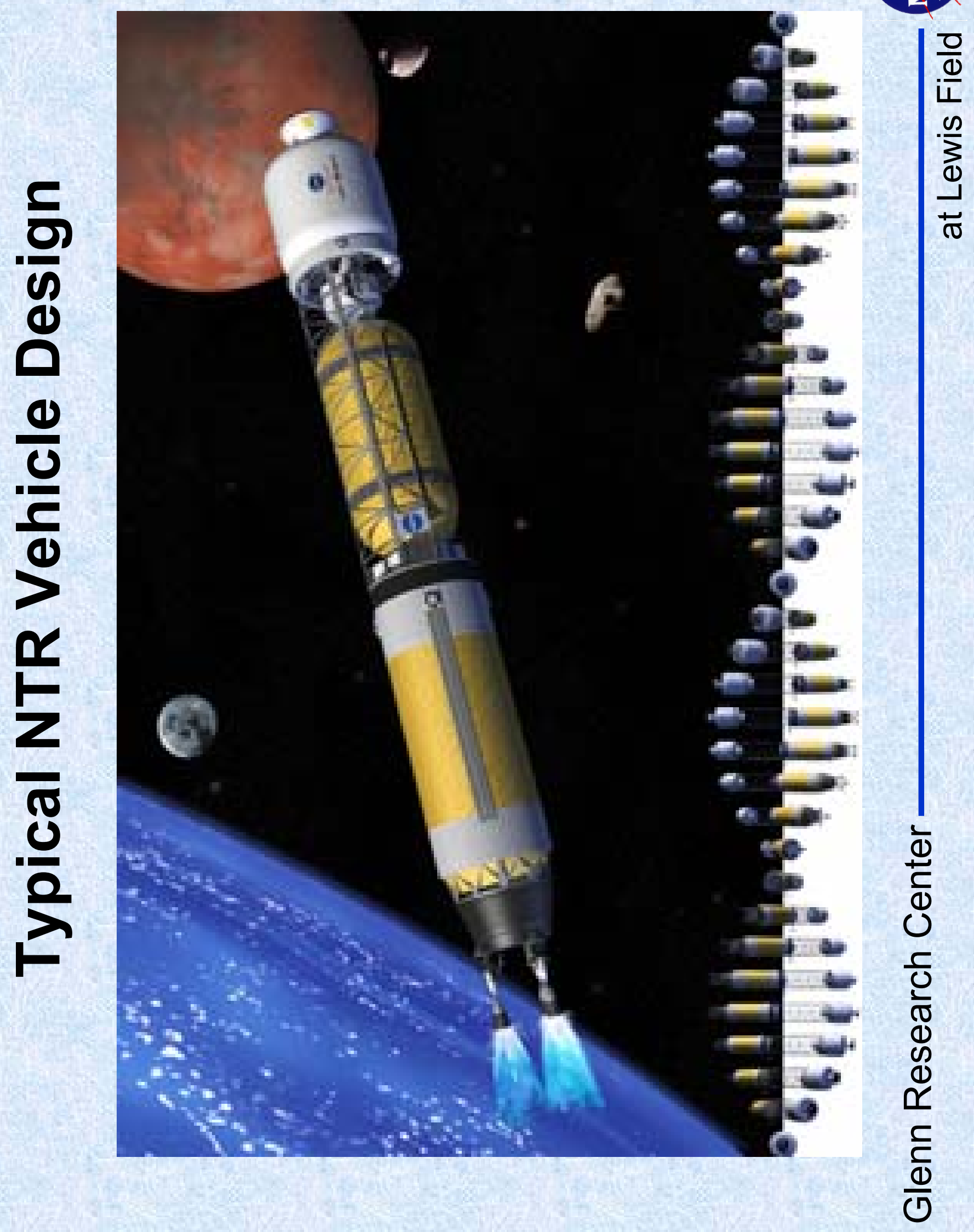

